\title{
Swedish Legislation Targeting Trafficking for Sexual Exploitation and the Possibilities for Implementation in Estonia
}

Jennifer E. Lyall

Follow this and additional works at: https://researchrepository.wvu.edu/etd

\section{Recommended Citation}

Lyall, Jennifer E., "Swedish Legislation Targeting Trafficking for Sexual Exploitation and the Possibilities for Implementation in Estonia" (2013). Graduate Theses, Dissertations, and Problem Reports. 7329.

https://researchrepository.wvu.edu/etd/7329

This Thesis is protected by copyright and/or related rights. It has been brought to you by the The Research Repository @ WVU with permission from the rights-holder(s). You are free to use this Thesis in any way that is permitted by the copyright and related rights legislation that applies to your use. For other uses you must obtain permission from the rights-holder(s) directly, unless additional rights are indicated by a Creative Commons license in the record and/ or on the work itself. This Thesis has been accepted for inclusion in WVU Graduate Theses, Dissertations, and Problem Reports collection by an authorized administrator of The Research Repository @ WVU. For more information, please contact researchrepository@mail.wvu.edu. 


\title{
Swedish Legislation Targeting Trafficking for Sexual Exploitation and the Possibilities for Implementation in Estonia
}

\author{
Jennifer E. Lyall
}

Thesis submitted to the Eberly College of Arts and Sciences at West Virginia University

in partial fulfillment of the requirements for the degree of

\author{
Master of Arts in History \\ Robert Blobaum, Ph.D. (Chair) \\ Katherine Aaslestad, Ph.D. \\ Joshua Arthurs, Ph.D.
}

Department of History

Morgantown, West Virginia

2013

Key Words: human trafficking, Estonia, Sweden, Swedish Solution, prostitution laws, prostitution criminalization, human rights 
All rights reserved

INFORMATION TO ALL USERS

The quality of this reproduction is dependent upon the quality of the copy submitted.

In the unlikely event that the author did not send a complete manuscript and there are missing pages, these will be noted. Also, if material had to be removed, a note will indicate the deletion.

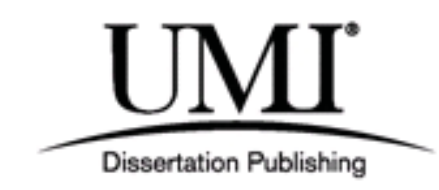

UMI 1549764

Published by ProQuest LLC (2013). Copyright in the Dissertation held by the Author.

Microform Edition (C) ProQuest LLC.

All rights reserved. This work is protected against unauthorized copying under Title 17, United States Code

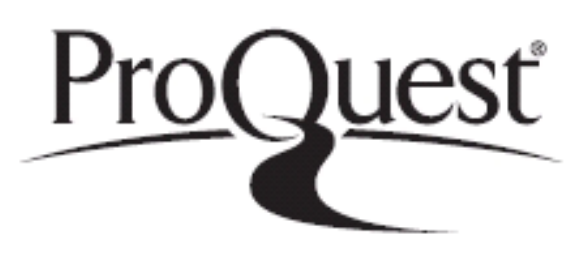

ProQuest LLC.

789 East Eisenhower Parkway

P.O. Box 1346

Ann Arbor, MI 48106 - 1346 


\title{
ABSTRACT
}

\section{Swedish Legislation Targeting Trafficking for Sexual Exploitation and the Possibilities for Implementation in Estonia}

\author{
Jennifer E. Lyall
}

Human trafficking is a human rights problem affecting all regions of the world. Various approaches have been utilized in attempts to eliminate the trade in human beings. In 1999, Sweden instituted a law to ban the purchase of sexual services, viewing prostitution as inherently violent and a contributing factor of human trafficking for sexual exploitation. This thesis determines that banning the purchase of sex is a legitimate and effective measure in combatting human trafficking for sexual exploitation. This thesis then discusses the Estonian sex industry and the possibilities for implementation of a similar sex purchase ban. Obstacles include Estonia's historical economic preferences and comparatively lower level of government involvement in social issues. At the present time, the Estonian government is increasing its participation in anti-human trafficking initiatives, the most important of which was the creation of a provision criminalizing human trafficking as a crime itself, rather than as an aggravating factor of another crime. There is also a debate in both civil society and on the governmental level concerning the legal status of prostitution. These developments indicate a possibility that Estonia could soon adopt a law similar to Sweden's, which would ban the purchase of sex. 


\section{Table of Contents}

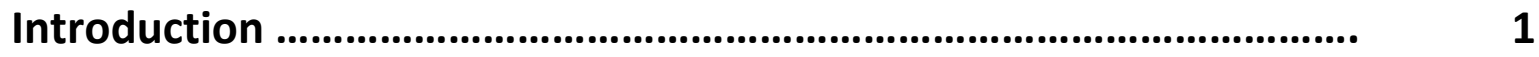

Historical Context of Human Trafficking ...............................................

Human Rights Context of Human Trafficking ....................................... 13

Theoretical Approach ............................................................................ 17

Sweden's Anti-Human Trafficking Legislation .................................... 35

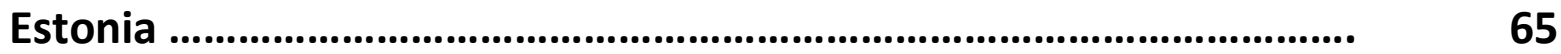

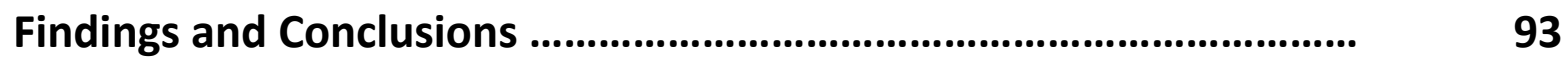

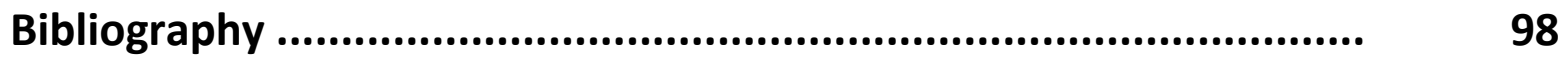




\section{INTRODUCTION}

Human trafficking is a global phenomenon affecting millions of people, despite the widespread belief in the permanent abolition of all forms of slavery. Despite recognizing this problematic phenomenon and attempting to craft appropriate and effective methods of prevention, human trafficking remains an elusive and profitable industry run by astute criminals who constantly change their tactics to take advantage of the weak points of local and international laws. These same people are also clever in their recruitment techniques, which focus on vulnerable individuals who are easier to exploit. This is a high-profit illegal trade that may or may not have punitive consequences equal to the crime. In countries where such crimes are unlikely to be prosecuted or lead to penalties unequal to the severity and profitability of the crime, the profit outweighs the punitive risks. Human trafficking should be made an unprofitable, high-risk enterprise in order to effectively reduce the number of incidences.

Statistics and measurements are a prominent problem in any discussion about trafficking in persons and effective strategies to combat it. Statistics are necessary to understand the scale and scope of the problem, but they are also impossible to compile with complete accuracy. There are many reasons for this. First, and a problem of its own, each and every aspect and factor involving trafficking must be defined in order to provide real and reliable data. Globally, these definitions are still not standardized, but there has been greater impetus to create universally-accepted definitions. ${ }^{1}$ The most influential contributors to the promotion of universality of law regarding human trafficking are the United Nations and the European Union.

\footnotetext{
${ }^{1}$ Kauko Aromaa. "Trafficking in Human Beings: Uniform Definitions for Better Measuring and for Effective CounterMeasures," in "Measuring Human Trafficking", edited by Ernesto U. Savona and Sonia Stefanizzi (New York: Springer 2007), 13-26.
} 
Basic definitions for human trafficking and their intended purposes are also in the process of becoming standardized and accepted. Contemporary and historical variations of definition present a problem on the global scale in identification and detection of victims, prosecution for perpetrators, and research upon which both theories and actions are based. For the purposes of this thesis, the definition by the United Nations Office on Drugs and Crime will be used, which is as follows:

The recruitment, transportation, transfer, harbouring or receipt of persons, by means of the threat or use of force or other forms of coercion, of abduction, of fraud, of deception, of the abuse of power or of a position of vulnerability or of the giving or receiving of payments or benefits to achieve the consent of a person having control over another person, for the purpose of exploitation. Exploitation shall include, at a minimum, the exploitation of the prostitution of others or other forms of sexual exploitation, forced labour or services, slavery or practices similar to slavery, servitude or the removal of organs. ${ }^{2}$

Additionally, difficulties are presented not only by non-standardization of the basic term, but also elements or aspects which are not defined, including words such as "choice", "force", and "free". These are terms about which even human trafficking experts and researchers are not in accord. When conducting research on victims, it is a fact that many do not regard themselves as victims - even as victims of circumstance. Many people that have been forced or coerced do not self-report as being forced. Self-reported surveys or interviews with prostitutes are not reliable, yet comprehensive data has not been collected by other means. Those who claim that these results are straightforward and dependable are misinterpreting the data and not considering all the facts and variables. In self-reported surveys, most women will not consider themselves as victims or sufferers of abuse. Perhaps

\footnotetext{
${ }^{2}$ United Nations Office on Drugs and Crime, Human Trafficking, October 30, 2008. http://www.unodc.org/unodc/en/human-trafficking/what-is-human-trafficking.html (accessed January 20, 2013).
} 
they are in denial, intimidated by their pimps, or do not understand how victimhood is defined.

It is possible that NGOs could choose to over-report or otherwise misconstrue their data in order to indicate need for funding or for other political reasons. Generally speaking however, NGOs are both the primary contacts for possible victims as well as the providers of the most relevant and complete information from the clients they have been working with, making them highly valuable resources and experts concerning developing trends. Individual governments could choose to skew data in the opposite way, under-reporting or repressing data for domestic political reasons or global reputation. It is in the best interests of all to produce and use proper, reliable data and admit the shortcomings of the data that are used. However, data manipulations are much less of a problem than the simple lack of standardized definitions and their applications, which is not a problem caused by malicious intent.

Human trafficking affects virtually all corners of the globe in some way or another, though it is often hidden from the sight of the average person. This illegal trade is extremely lucrative. Not only does one group of people oppress another and cause unimaginable suffering, but they also profit from this misery. There are connections between human trafficking and other forms of organized crime, such as arms and narcotics trafficking. ${ }^{3}$ Human trafficking causes human suffering, undermines governmental and international authority, funds organized crime, and displaces individuals from their homelands, causing population loss. In the supposedly post-slavery world in which all people have natural rights, human trafficking is not supposed to exist.

\footnotetext{
${ }^{3}$ This does not have to be the case, but it often is. Human trafficking operations exist in various sizes. For more information, please refer to Chapter 19, “The Impunity of Peace” in Louisa Waugh's book Selling Olga (2006).
} 
The purpose of this thesis is to highlight the anti-human trafficking legislation enacted by two countries - Estonia and Sweden. Specifically, this thesis will focus on trafficking for sexual exploitation. Sweden is a prime example of one extreme of the proposed solutions to trafficking for sexual exploitation and prostitution. Sweden is often cited as a pioneer in anti-trafficking approaches. The Swedish example is influenced by feminist ideology which in 1999 banned the purchase of sex and criminalized the buyer.

Estonia has prosecuted human trafficking with a different approach, which is currently in the process of becoming further developed and codified. Previously, traffickers were prosecuted under laws against trafficking-related crimes but not human trafficking itself as a crime. In 2012, a new provision was introduced targeting human trafficking. This legal change has come after criticism by the annual Trafficking in Persons Report (TIP Report) published by the U.S. Department of State. Human trafficking is increasingly becoming a topic discussed in the media in Estonia, indicating a raising level of public awareness. Additionally, after years of legal ambiguity, the matter of how to handle prostitution has become a question in the public consciousness. Because of the impetus and for legal change and the legal "blank slate" concerning prostitution in Estonia, it is worth examining if there is a possibility to recreate the Swedish solution in Estonia.

It is important that as neighbors on the Baltic Sea, these two countries share the problem of human trafficking. Human trafficking networks often operate regionally and through uncomplicated transport means to avoid detection and maintain high profit margins. Sweden is mainly a destination country for trafficked persons, whereas Estonia 
functions as a point of origin for trafficking victims, a destination, and a country of transit. ${ }^{4}$ There is a sizeable percentage of Estonian trafficking victims represented in Sweden. Any anti-human trafficking policy change made in one country will affect the other. Therefore, it is in the interests of both countries to push for more effective laws.

It became evident in other research projects that the there is still much debate over prostitution and its relationship with human trafficking for sexual exploitation. This thesis explores the following questions, which are in relation to this original query: What are the approaches of Sweden and Estonia? Is the theoretical framework of Sweden's sex purchase ban supported by evidence? Is the approach, as implemented by Sweden, an effective one? What is the role of the sex industry in human trafficking for sexual exploitation? Would Estonia, and theoretically other states as well, be able to benefit by adopting and emulating Swedish policies? Finally, what would push Estonia to adopt a ban on the purchase of sexual services?

In order to answer these research questions this thesis shall begin with a section examining the historical context of human trafficking, including information concerning its relationship with slavery and "white slavery". It shall then focus on human rights in the context of human trafficking. In order to provide context for the current Swedish legislation, the historical context of the ban on the purchase of sexual services and the theoretical background of the present legislation shall be presented. There follows a discussion of Sweden's actual legislation, its efficacy, and the criticism it has incurred. The focus shall then shift to Estonia, including an overview of its history and the implications of that history on the current policies regarding human trafficking and prostitution. A discussion of

\footnotetext{
${ }^{4}$ For example these persons may be from countries such as Ukraine and Russia. Due to its location on the Eastern edge of the Schengen Zone, the border of Estonia becomes important for all countries party to the Schengen Agreement.
} 
Estonia's anti-human trafficking legislation, recently changed, will follow, with research on Estonia's sex industry included. 


\section{Historical Context OF HUMAN TRAFFicking}

"Human trafficking" is a term which has incited a slew of debates regarding definition. At the present time, there is no one cohesive definition. Even when institutions and states rely upon the same definition, they often interpret and implement the information in varied ways. The most significant hindrances to cohesively defined and prosecuted human trafficking today are political, often due to denial of the problem or ideological dissonance. ${ }^{5}$ The hysteria-inducing "white slave trade" is often cited as the beginning of modern awareness of human trafficking. "White slavery" became a euphemism for the situation of women exploited in prostitution, usually abroad, and was accompanied by tales which morally shocked society at the time. This was the meaning of the phrase as it was used in an international agreement with the aim of suppressing "white slave traffic" in 1904.The legal acts pertaining to the "white slave" trade were primarily focused on third parties transporting prostitutes across borders and foreign prostitutes.

There was panic over "white slavery" throughout Europe in the late $19^{\text {th }}$ century, after industrialization and population movement to urban areas. In late nineteenth-century Russia, for example, prostitution was common among working-class women attempting to earn enough money to live. Working conditions for Russian women were particularly bad and there was an increase in prostitution. ${ }^{6}$ Many contemporary Russians could not understand that it was economic vulnerability which pushed working-class women into the sex industry and believed that there must have been a scheme of organized prostitution employing devious methods to lead innocent young women astray. The peasantry was often

\footnotetext{
${ }^{5}$ From its introduction as "white slavery" as opposed to viewing human trafficking from the lens of "slavery".

${ }^{6}$ Bernstein, Laurie, Sonia's Daughters: Prostitutes and Their Regulation in Imperial Russia (Berkeley: University of California Press, 1995).
} 
viewed with a particular romanticism, which was then applied to prostitutes. " White slavery" was synonymous with brothel prostitution; many believed that the women had been forced into the Russian sex industry through "kidnapping, drugging, and beating". ${ }^{8}$ In reality, "brothel life involved less sensational kinds of oppression," such as "debt peonage, exploitation, and disease." "White slavery" myths in the Russian Empire also bore antiSemitic implications as it was accompanied with a myth that the main perpetrators were Jews. ${ }^{10}$

The Austrian Empire also had such myths regarding the "white slave trade" ${ }^{11}$ Many young women were trafficked from poor areas of the empire to the primary destinations of South America (particularly Argentina and Brazil), the United States, Egypt, Singapore, Shanghai, and Hong Kong. ${ }^{12}$ Weak economies in parts of the empire led to a large number of women pursuing immigration. ${ }^{13}$ Their economic desperation and willingness to travel made them easy targets for traffickers who promised them assistance. Once they reached their destinations, they were kept in brothels usually owned by fellow nationals. ${ }^{14}$ As elsewhere in Europe, there was intense interest and debate in the "white slave trade". This led to international agreements (through the League of Nations) as well as domestic

\footnotetext{
${ }^{7}$ Ibid, 6-7.

${ }^{8}$ Ibid, 10.

${ }^{9}$ Ibid.

${ }^{10}$ Ibid.

${ }^{11}$ Mädchenhandel in German

12 Jürgen Nautz, "The Effort to Combat the Traffic in Women in Austria before the First World War," Journal for Police Science and Practice, 2 (2012), 82-83.

${ }^{13} \mathrm{Ibid}, 83$.

${ }^{14}$ Ibid, 84.
} 
policies. ${ }^{15}$ For example, in 1904 The Office for the Suppression of the International Traffic in Young Women was created in Vienna. ${ }^{16}$

The hysteria that this topic caused was accompanied by "almost identical" narratives "throughout the transatlantic area," but these also coincided with some aspects of the "white slavery" myths in the Russian Empire. ${ }^{17}$ In addition, Jews were often cited as culprits in these myths, a phenomenon continuing today among fringe groups promoting racial hierarchies. ${ }^{18}$ Particularly, there was a lack of agency for women. While they were deceived and trafficked into the sex industry, they were easy to mislead because of their economic situations, not because they were women who knew no better and required protection.

Thinking about the issue of "white slavery" was influenced mainly by such activists as Josephine Butler in Britain. In the case of Butler - possibly the most influential person in the fight against the "white slave trade" during both her own time and the years following she campaigned was for the repeal of the British Contagious Diseases Act, which subjected prostitutes to state control. A registry of women working as prostitutes was kept, ostensibly blacklisting said women for the rest of their lives should they attempt to find other work or socialize. ${ }^{19}$ Arrest followed by invasive and forced medical inspection could be applied to women who merely seemed to be prostitutes, violating women in the interest of supposedly keeping soldiers healthy and free of sexually transmitted infections and diseases. Butler was extremely influential in not only repealing the Contagious Diseases Act, but also pushing forward the White Slave Act of 1904 and later the International Convention for the

\footnotetext{
${ }^{15}$ Ibid, 82.

${ }^{16} \mathrm{Ibid}, 87$.

${ }^{17}$ Ibid, 89-90.

${ }^{18}$ Simply doing a Google search with terms "white slavery" can bring up a a number of right-wing opinion pages.

${ }^{19}$ Anne Summers, "Which Women? What Europe? Josephine Butler and the International Abolitionist Federation," History Workshop Journal 62 (Autumn 2006): 214-231.
} 
Suppression of the White Slave Traffic in 1910, intended on her part to protect women. ${ }^{20}$ Butler's attempts to establish an organized network internationally were not as successful as she might have hoped. It is possible that the political and religious climates of the time were not conducive for feminists in countries other than Britain, which was noted to be more advanced in terms of gender equality. ${ }^{21}$ Butler did succeed in the creation of a lasting legacy for abolitionism. ${ }^{22}$

Both contemporaneous and modern negative interpretations of the laws enacted against "white slavery" posit the stance that these laws were meant to restrict the movement of women, shut them out of the international job market, and effectively render them more reliant on the wealth and status of the men in their lives. Modern detractors see correlations between laws created in the early $20^{\text {th }}$ century against white slavery and current laws that ban prostitution in some countries, such as Sweden. Such thinking is supported by the "sex work" group of Liberal Feminists, who argue that prostitution is a legitimate profession and can be freely chosen. They believe that such work is liberating for women, who are now in control of their sexual identities. ${ }^{23}$ Furthermore, they argue that when prostitution is banned, an inevitable consequence is harm to the prostitutes that the laws claim to protect. A contrasting feminist interpretation centers upon the intended protection of women and girls from forced prostitution, in particular across borders. This group is termed abolitionist. Following their theories and reasoning, prostitution is not a choice and is not liberating; rather it is forced or coerced and inherently degrading. The selling of sex is believed to be

\footnotetext{
${ }^{20}$ United Nations, "International Convention for the Suppression of the White Slave Traffic," United Nations Treaty Collection, May 4, 1910.

${ }^{21}$ Summers, 220.

${ }^{22}$ Summers.

${ }^{23}$ Jo Doezema, "Who Gets to Choose? Coercion, Consent, and the UN Trafficking Protocol," Gender and Development 10, 1 (March, 2002): 20-27.
} 
commodification of women and their bodies to the will and whim of men, giving them further hegemony. Abolitionists usually believe that human trafficking is amplified by legalized prostitution.

The argument that state-regulated prostitution contributes to human trafficking for the purposes of sexual exploitation is not a new one; the League of Nations' Advisory Committee on the Traffic of Women and Children (1919-1945) condemned the regulated sex industry, claiming that "state-regulated prostitution [was] the cause of the international traffic in women and children." ${ }^{24}$ The Advisory Committee emerged at the end of the First World War and was the result of the impetus for increased international cooperation. Where Butler's international campaign had floundered, this new movement was able to utilize an international structure - the League of Nations - to further the cause and message. The anti-trafficking movement of the era remained concerned with "an equal standard of morality that required men and women to be judged based on expectation of similar sexual behavior", recognition of men as complicit in the act of prostitution, and the abolition of the state-regulated sex industry that supported the trafficking of women internationally. ${ }^{25} \mathrm{In}$ general, laws which targeted women disproportionately were subject to scrutiny and protested as state-sponsored discrimination and contribution to societal inequality. "White slavery" has been viewed as an international rallying point for feminists of the era seeking equal opportunity and status as men, including individual citizenship not based on that of their male relations. ${ }^{26}$ Unfortunately, after making progress for the years the organization

\footnotetext{
${ }^{24}$ Jessica R Pliley, "Claims to Protection: The Rise and Fall of Feminist Abolitionism in the League of Nations' Committee on the Traffic in Women and Children, 1919-1936," Journal of Women's History 22, 4 (2010): 90-113; 91. Emphasis original.

${ }^{25}$ Pliley, 92.; Summers, 220

${ }^{26}$ Pliley, 91.
} 
was active, growing nationalism is argued to have been the factor which diminished the power of internationally-minded groups. ${ }^{27}$

Human trafficking can also be interpreted as the modern equivalent of slavery, as many contemporary organizations do ${ }^{28}$ Anti-slavery debates reached a climax during the era of the Atlantic slave trade following the Enlightenment which shook Western societies to the root. The ideas put forth by the likes of Kant, Locke, and Paine were revolutionary, the most powerful being the position of inherent natural rights on the basis of birth. When these ideals were put into practice the results were explosive, resulting in the re-shaping of societies and the birth of human rights. Inspired by the Declaration of the Rights of Man and Citizen passed in 1789, the French Revolution occurred roughly during the years 1789 to 1799 . This document contains 17 articles which are highly influential to human rights. The Articles include human rights we have come to assume are basic, such as: (1) "Men are born and remain free and equal in rights," (2) rights to "liberty, property, security, and resistance to oppression," (4) the ability to exercise personal liberties that do no harm to other persons, and (5) the law may only prevent that which harms society and (6) that the law be an "expression of the general will".${ }^{29}$ Human rights would become an important contribution to the discussions on slavery and human trafficking.

\footnotetext{
${ }^{27}$ Pliley, 92.

${ }^{28}$ Such as the Polaris Project, an anti-human trafficking NGO.

${ }^{29}$ National Assembly of France, "Declaration of the Rights of Man,"(1789) The Avalon Project: Documents in Law, History, and Diplomacy, Yale Law School (2008).
} 


\section{Human Rights ConteXt OF Human TrafFicking}

Following the Second World War, the Universal Declaration of Human Rights was adopted by the United Nations General Assembly in $1948 .^{30}$ Enlightenment ideals were still present in the Universal Declaration of Human Rights which was influenced directly by the French Rights of Man and Citizen. These thirty articles outline the basic rights of all people. ${ }^{31}$ The UN has been highly influential in combatting human trafficking and has used the ideals of the Universal Declaration of Human Rights to create other documents solely dedicated to combatting human trafficking.

The primary of these is the Palermo Protocol, adopted on November $15^{\text {th }}, 2000$ by the UN General Assembly. This was a major step in creating awareness of human trafficking and addressing the subject in an international context and supplements the United Nations Convention against Transnational Organized Crime. ${ }^{32}$ Article 5 gave each country the responsibility to fight human trafficking through "legislative and other measures", while Article 6 included measures for the support and protection of human trafficking victims. ${ }^{33}$ There are also articles addressing repatriation of victims (Article 8), measures to prevent human trafficking (Article 9), and border measures (Article 11). The Protocol addressed many important legal and jurisdictional complexities which required international cooperation and consensus, as well as addressing human trafficking in a

\footnotetext{
30 United Nations, "The Universal Declaration of Human Rights," December 10, 1948. http://www.un.org/en/documents/udhr/ (accessed March 20, 2013).

31 lbid.

32 United Nations, "Protocol to Prevent, Suppress and Punish Trafficking in Persons, Especially Women and children, Supplementing the United Nations Convention Against Transnational Organized Crime," United Nations Convention Against Transnational Organized Crime and the Protocols Thereto, New York, 2004.

${ }^{33}$ Ibid.
} 
human rights context. Due to its complex view of the problem, it has created a vital precedent for addressing human trafficking.

However, the Palermo Protocol only narrowly succeeded after disagreements between polarized ideological groups. The main point of contention was whether prostitution could be freely chosen as a legitimate profession. Those parties that considered prostitution as a possible freely chosen profession included some NGOS (those which followed "sex work feminist" ideology) and governments of countries with regulated or legalized prostitution industries. The goal of these groups was to create a protocol which omitted any mention of trafficking for sexual exploitation. ${ }^{34}$ Initially, individuals involved with the decision-making process, such as the UN High Commissioner for Human Rights, "also favored deleting the term sexual exploitation to avoid the implementation difficulties inherently associated with undefined, imprecise and emotive terms such as sexual exploitation when used in connection with adults". ${ }^{35}$ The International Labour Organization was also in favor of the omission of the phrase "sexual exploitation." ${ }^{36}$ Other UN bodies urged the committee deciding on the phrasing of the law to reconsider its stance on the status of victims of human trafficking for sexual exploitation. ${ }^{37}$

In particular, there was a strong discord between the stance taken by the committee and the 1949 Convention for the Suppression of the Traffic in Persons and of the Exploitation of the Prostitution of Others. ${ }^{38}$ The Committee preferred to only include as

\footnotetext{
${ }^{34}$ Janice G. Raymond, "Guide to the New UN Trafficking Protocol," Coalition Against Trafficking in Women, 2001, 4.

${ }^{35}$ Ibid, 6.

${ }^{36}$ Ibid.

${ }^{37}$ Ibid.

${ }^{38}$ United Nations, "Convention for the Suppression of Traffic in Persons and of the Exploitation of the Prostitution of Others," United Nations Treaty Series, (New York: United Nations, March 21, 1950).
} 
victims those who were subjected to force or coercion and could furthermore prove such treatment. However, Article I of the 1949 Convention states:

The Parties to the present Convention agree to punish any person who, to gratify the passions of another:

1. Procures, entices or leads away, for purposes of prostitution, another person, even with the consent of that person;

2. Exploits the prostitution of another person, even with the consent of that person. ${ }^{39}$

This would validate the inclusion of a prostitution debate and the inclusion of trafficking for the purpose of sexual exploitation, especially in regards to the grey area of choice or perception of choice. According to the 1949 Convention consent makes no difference. This also makes the Dutch and German laws regulating prostitution in direct conflict with the ideas expressed in the Convention. Specifically, countries with legalized and regulated prostitution are not adhering to the spirit of Articles 1, 2, and 3 of the Convention. Articles 2 and 3 are as follows:

\section{Article 2}

The Parties to the present Convention further agree to punish any person who; 1. Keeps or manages, or knowingly finances or takes part in the financing of a brothel;

2. Knowingly lets or rents a building or other place or any part thereof for the purpose of the prostitution of others.

\section{Article 3}

To the extent permitted by domestic law, attempts to commit any of the offences referred to in articles 1 and 2, and acts preparatory to the commission thereof, shall also be punished. ${ }^{40}$

\footnotetext{
${ }^{39}$ UN General Assembly, "Convention for the Suppression of the Traffic in Persons and of the Exploitation of the Prostitution of Others," 1949.

${ }^{40} \mathrm{Ibid}$.
} 
This argument would be countered by proponents of prostitution as legitimate work by arguing that such agreements were based upon a desire to restrict and control the movement of women, rather than to protect them, as well as possibly describing the Convention as outdated and preserving dated social standards for women's autonomy. ${ }^{41}$

Several groups involved in negotiations of the Palermo Protocol favored the inclusion of cases of human trafficking for sexual exploitation. Some NGOs favored the clause's inclusion out of ideological concerns and a desire to impact policy-making in accordance with their views. Governments from source countries of human trafficking victims favored inclusion for protection of their people, while those which had criminalized prostitution were in also in favor. ${ }^{42}$ The resultant Protocol was a compromise which provided a definition that included trafficking for sexual exploitation or prostitution but simultaneously afforded each ratifying country the autonomy to manage the prostitution question independently, despite Article I of the 1949 Convention. ${ }^{43}$ Since 2000 there have been minor changes to the international agreement as the debate continues. Every country maintains their own laws concerning human trafficking, in addition to the responsibility to honor the values highlighted in the Protocol.

\footnotetext{
${ }^{41}$ Doezma.

${ }^{42}$ Raymond, 4.

${ }^{43}$ Ibid, 5.
} 


\section{THEORETICAL APPROACH}

This thesis takes a variety of theoretical approaches to discuss human trafficking. The use of a multidisciplinary approach is necessary to fully recognize the causes and effects of human trafficking and to develop effective strategies against it. ${ }^{44}$ To use a single theory would constrain the discussion and create blind spots in understanding. Instead, this thesis is focused on examining practical solutions and shall therefore use various theories to explain the different and complex pieces of this issue. Trafficking in persons is the result of many factors, including cultured gender roles and beliefs, social hierarchies which vary across cultures, the economic situations of victims and of perpetrators, and above all the role of power and power affirmation. Previous research has indicated that long-standing factors of human trafficking include gender, age, political instability, globalization, capitalism, poverty, education, culture, domestic violence, corruption, war, and immigration difficulties. ${ }^{45}$

To truly understand why the sex industry does indeed promote human trafficking for sexual exploitation, feminist gender construction theory is highly useful. Every culture has unique, socially-constructed gender norms, many of which support gender inequalities. Sexual exploitation and violence are directly related to socially-constructed gender inequalities. The number of women that report abuse varies by country and definition, but the statistics are generally shocking and indicate a real and palpable problem in the lives of

\footnotetext{
${ }^{44}$ Elizabeth M. Wheaton, Edward J. Schauer, and Thomas V. Galli, "Economics of Human Trafficking," International Migration, 48, 4 (2010): 114-141.

${ }^{45}$ Ibid, 121-123.
} 
women and girls. There is increasing evidence that men use violence, including sexual violence, to assert their authority over the victim. ${ }^{46}$

There is a growing body of research which confirms that gender roles contribute to men's attitudes about women and sex and the intersection between them. These vary by culture. However, in societies that define masculinity through sexual prowess, there is a distinct correlation with both legalized prostitution and with sexual violence. Societal attitudes about prostitution and its acceptability are formed by gender norms, which in turn inform society what is acceptable. Ricardo and Barker's study asserts that masculinities and gender norms are socially constructed, vary according to "historical and local contexts," and join "other factors such as poverty and globalization." ${ }^{47}$ In this theoretical framework, gender norms "emerge from prevailing patterns of hegemony and patriarchy," and are then maintained and mimicked by influential social groups and institutions. ${ }^{48}$

Gender norms are internalized by children, who attempt to imitate the roles they see as representative of their gender identity. Men and boys are often socialized to believe that masculinity is based in sexual prowess. ${ }^{49}$ They are also taught that femininity is the opposite of masculinity, and therefore the opposite of what they should aspire to be. Svensson and Gunnarsson indicate that "empirical observations identified the subordination of women as underpinning an organisational pattern in society," which was supported by two notions: 1)

\footnotetext{
${ }^{46}$ Victims can be of any gender or age. In cases of sexual violence between men, there is still a power and social dominance motivation. Most male sexual violence is perpetrated by males that self-describe as heterosexual. An act of sexual violence by a heterosexual male against another male is not a simple act of sexual desire; it is instead an expression of his hegemony and superiority, be it economically, socially, or as a demonstration of masculinity. These motivators are often the same for the sexual violence perpetrated against women. Thus, social domination through masculinity becomes an integral motivator of sexual violence.

${ }^{47}$ Christine Ricardo and Gary Barker, "Men, Masculinities, Sexual Exploitation and Sexual Violence: A Literature Review and Call for Action," MenEngage (Rio de Janeiro: Promundo, 2008).

${ }^{48}$ Ibid.

${ }^{49} \mathrm{Ibid}, 4$.
} 
the notion of a "separation of the male and the female," 2) belief that male was the standard by which both should be judged, rendering female undesirable simply for the fact that is it not male.$^{50}$ Female becomes "bad" while male is "good". Women and girls are expected to be submissive and lack an interest in sex while men should exhibit "displays of sexual competence or accomplishment". ${ }^{51}$ There is also the socially expected and accepted masculine lack of control over sexual desire. ${ }^{52}$

By deeming female sexual desire as deviant and socially unacceptable, women are not given agency over their own bodies and are denied "full citizenship" in society. ${ }^{53}$ Their bodies become public property to be presided over and judged. ${ }^{54}$ This removes control from women and gives it to men who presuppose a "right" to objectify women in a variety of ways. This "objectification and commodification" of both women and sex, particularly when combined with issues of masculinity and control, creates an environment in which women become commodities themselves and "a broader spectrum of sexual behaviors, including more violent and coercive ones," become dangerously normalized. ${ }^{55}$

It should be noted that women used in advertising are often "portrayed as objects of sexual desire," subliminally implying that by buying the product, one is in fact buying access to the woman that was made available through the advertisement. ${ }^{56}$ This attitude only promotes the idea, though in an unconscious way, that it is acceptable to buy and use other human beings.

\footnotetext{
50 Ibid.

${ }^{51}$ Ricardo and Barker, 4.

52 Ibid.

53 Ibid.

54 Ibid.

55 Ibid, 34.

${ }^{56}$ Ariel Levy, Female Chauvinist Pigs (New York: Free Press, 2006), 26; Giselle Routhier, "Understanding The Demand For Human Sex Trafficking: A Study Of Attitudes Regarding The Commercial Sex Industry," Social Work Theses, Paper 11, (Providence College. April 24, 2007), 10-11.
} 
Evidence supports the theory that purchase of sex is inherently exploitative due to its conveyance of a message of power relations combined with lack of true choice on the part of the sex seller; this is a physically manifested form of economic and social dominance that one party holds over another. Boys are cultured to believe that "real men" must act in a particular way and have a particular set of urges and values. Most common is the sociallyreinforced machismo surrounding sexual behaviors and attitudes. Men are supposed to have insatiable sexual desire; they should be free to express this desire and to fulfill it, and they are unable to control themselves due to their biology. The more sex they have with as many partners as possible, the more masculine they are and therefore the better they are. Sexual experience is highly regarded.

Women are constructed to be the opposite of men, and thus their behaviors must be the opposite. Boys are raised with the idea that properly feminine women do not process the same sexual desire as men. These virginal women are "good women," while women who do want sex are constructed as dangerous "bad women". This also supports the notion that men who do not want sex constantly are not real men; they are women or girls. Gendered violence is "driven by social norms related to gender and sexuality and the unequal power dynamics between men and women that these norms create and reinforce." ${ }^{57}$ The sex industry also reinforces these roles and attitudes, as it is "driven or motivated by men's sexuality and sexual behavior." ${ }^{58}$ Women's sexuality is commodified for consumption by men, normalizing the act and the thought that women are objects for male sexual gratification. ${ }^{59}$

\footnotetext{
${ }^{57}$ Ricardo and Barker 3.

58 Ibid.

$59 \quad$ Gunilla Ekberg, "The Swedish Law That Prohibits the Purchase of Sexual Services: Best Practices for Prevention of Prostitution," Violence Against Women 10, 10 (October 2004): 1187-1218; 1187-1196.
} 
By allowing the purchase of sex to be legal, societies create an environment where an in-group (mostly men in this case) will continue to be socialized into the idea that they are privileged in society and the out-group, mainly women and girls, will continue to be considered as second-class citizens at best and subhuman at worst. ${ }^{60}$ Victims become a commodity. In addition, prostitutes are always a societal out-group; they are used by those who purchase them for sex but are blamed for their own victimhood. Due to their nature as a group subject to oppression and abuse through power relations, they can never be an ingroup. Even in countries such as Germany and the Netherlands, prostitutes are not completely accepted in society, despite their supposed decisions that prostitution should be considered a legitimate profession. This negates any argument that an individual should be allowed to voluntarily ${ }^{61}$ sell sex; in doing so she perpetuates the misogynistic attitudes of men against women. In this situation, the rights of others are endangered.

The two most important theories are those which have been the most active in the past 15 years in anti-trafficking and prostitution debates. These are associated with the Liberal sex-work feminists and the radical feminists of Swedish tradition. Legalized prostitution and gender imbalance create the myth that men are entitled to sex and women's bodies, and that masculinity is defined primarily through sexual prowess. ${ }^{62}$ Because men believe that these behaviors and attitudes are acceptable, the demand for paid sex increases. ${ }^{63}$ When the demand for paid sex increases, profit-seekers will attempt to meet this demand in a way that is as profitable for them as possible.$^{64}$ This is through trafficking, as

$60 \quad$ Judith Butler, Gender Trouble, (New York: Routledge, 1999).

${ }^{61}$ This in the sense of having truly free choice, not a decision guided by force of circumstance.

${ }^{62}$ Ekberg, 1187-1188.

63 Erin O'Brien, "Fuelling Traffic: Abolitionist Claims of a Causal Nexus Between Legalised Prostitution and Trafficking," Crime, Law and Social Change 56, 5 (December 2011): 547-565.), 558.

${ }^{64}$ Ibid. 
the "demand for sexual services and the normalisation of prostitution through legalisation or decriminalization act as 'pull' factors that fuel the global trade in women and children." ${ }^{65}$

The research for this thesis supports some views proposed by the Swedish radical feminists which informed the national law banning the purchase of sexual services. There is ample evidence to support the theory that prostitution is a manifestation of violence. Such violence is used as both an instrument of and a physical display of the power of the sex purchaser over the person in prostitution. In the majority of cases, men are perpetrators of sexual exploitation and violence against victims that are usually women or girls." ${ }^{66}$ If on the surface the purchase of sex appears to be purely an expression of physical and sexual power, it is symbolic of social and economic dominance. This behavior is "driven by social norms related to gender and sexuality and the unequal power dynamics between men and women that these norms create and reinforce. ${ }^{167}$ Additionally, Swedish radical feminism rejects the idea that sex work may be freely chosen as a fulfilling profession. Given the evidence researched for this thesis, this argument is also supported. The idea of truly free choice must be considered, as it is in Marxist theory.

A Marxist approach to trafficking in persons is effective in rationalizing the economic disparities which increase the incidence of human trafficking. In particular, Marxist theory can be applied to the movement of labor and the treatment of workers. Demand for cheap labor in developed nations creates an environment in which labor is exploited more freely. Combined with poor economies in other states and strong desires for immigration in the pursuit of a better life, human trafficking in all its forms becomes a

\footnotetext{
${ }^{65}$ Ibid, 547.

${ }^{66} \mathrm{Ibid}$. However, it is important to recognize that while the majority of occurrences are men purchasing sex from women, this is not always the case. Sexual violence committed by men against other men occurs for the same reasons.

${ }^{67}$ Ibid.
} 
consequence. Intended migrants trust smugglers to safely conduct them over borders. In some cases these smugglers are actually traffickers, selling those migrants into servitude instead. Those who find themselves in the lower class (migrants sold into servitude) are subjected to the oppression of the upper class (buyers of trafficked people), which exploits their labor to its own benefit.

A useful contribution of Marxist theory to the understanding of human trafficking is in its discussion of free choice. What constitutes truly free choice? As Kendra Strauss explained, there is a "continuum of exploitation", in which there exist levels of abuse which are perceived more and less negatively based upon the ideals of the time and location of those making the assessment. ${ }^{68}$ There is a cultural aspect in the grey area of unfreedom, and what is now considered free by the majority of people in a given place does not necessarily correlate with what would have been understood as freedom in years before. The Enlightenment era is when the biggest shift occurred in Western thinking.

This question is not as easily applicable to most human trafficking purposes which are obviously forced or coerced, but it is valid in the modern feminist debates whether prostitution is essentially unfree labor or as a legitimate and unforced profession. Marx recognized that "commodified labour under capitalist relations of production was and is not truly free labour," due to the fact that workers were "compelled to commodify their labour, having no access to the means of production or subsistence." ${ }^{69}$

This question of free and unfree choice is abstract but highly relevant to cases of human trafficking, particularly to the discussion of prostitution and sexual exploitation. ${ }^{70}$

\footnotetext{
$68 \quad$ Kendra Strauss, “Coerced, Forced and Unfree Labour: Geographies of Exploitation in Contemporary Labour Markets," Geography Compass 6, 3 (March 2012): 137-148; 138-139.

${ }^{69}$ Ibid, 139.

${ }^{70}$ In other words, is all prostitution inherently sexual exploitation?
} 
Debates over what constitutes free will cause structural problems in the context of definition in legal codes. Thus, according to Klara Skrivankova, "practical responses and policy need to address the problem as a continuum between decent work and forced labour, as an issue of both labour (and human) rights and criminal justice." ${ }^{71}$ While "lack of viable economic alternatives" may not constitute forced labor, economic helplessness which may be abused by a trafficker to gain a strained consent removes true freedom of choice from the victim and should be considered a form of forced labor on such a continuum. ${ }^{72} \mathrm{~A}$ trafficked person may be unlikely to self-report to being forced or un-free for a variety of reasons including intimidation, denial, misunderstanding of truly free choice, a desire to maintain their own illusions regarding their circumstances, or other individual reasons. Truly free choice can only be one which is not influenced by factors such as economic desperation. For example, if a woman becomes a prostitute because she feels she has few or no other options, then this was not forced on her by another person. It was not, however, a truly free choice.

Liberal sex work feminists have been adamantly against any state legislation which would criminalize sex purchase, citing that it endangers prostitutes and revokes their agency as human beings exercising free will. ${ }^{73}$ Sex work feminists believe that female sexual liberation includes the right to sell sexual services and that criminalizing the industry makes people who have chosen to work in it suddenly be treated as victims. Statements from current prostitutes supporting the sex industry are often accepted as accurate testimony. Perhaps these individuals are being paid by another to support the public face of the industry. They may also have a stake in the continued legal status of the industry in

\footnotetext{
${ }^{71}$ Klara Skrivankova, "Between decent work and forced labour: examining the continuum of exploitation," JRF programme paper (York, UK: Joseph Rowntree Foundation, 2010), 17.

${ }^{72} \mathrm{lbid}, 19$.

${ }^{73}$ Ricardo and Barker, 41.
} 
countries such as Germany and the Netherlands. Or perhaps they themselves do not admit the circumstances which led them to the sex industry or why they remain. Their testimonies contrast with those given by individuals who have left the sex industry, indicating that there is a change in mentality that accompanies a break from the sex industry. This is not to say that all those working in the sex industry are victims of circumstance. It is reasonable to assume that some persons do enter into the sex industry of their own accord, though the percentage must be quite low.

What is truly free choice? Have these women been able to exercise complete personal autonomy freely? Truly free choice cannot be influenced by circumstance. If a person feels that they have no legitimate options by which to support themselves and subsequently enter prostitution, it is not a truly free choice. This is often the case for those working in the sex industry. Many say "they were "forced" into prostitution because of unemployment, because they were underpaid, or because they labored under other desperate economic situation. ${ }^{174}$ Vulnerability is a powerful condition to exploit. ${ }^{75}$ Substandard options become those which one merely accepts, creating the illusion of choice. Instead of asking those in the sex industry if they chose this means of supporting themselves - as this is most often an issue of economy - or if they seek other, legitimate options, there is another set of questions which could be asked to find a more truthful answer. Perhaps the most telling question would be if they had aspirations as children, as most children do. It is doubtful that any of them would respond that they dreamt of becoming a prostitute. Working in the sex industry because one feels they have no legitimate option is a choice, but it is not a free choice, a distinction that challenges the assumption that prostitution is voluntary. What results is a

\footnotetext{
${ }^{74}$ Min Liu, "Chinese Migrant Women in the Sex Industry: Exploring Their Paths to Prostitution," Feminist Criminology, (September 16, 2012): 327-349; 329.

${ }^{75}$ Skrivankova, 19.
} 
state of unfreedom due to the inability of a group of people to commodify their labor. ${ }^{76}$ Additionally, prostituted people are not fully free to leave the sex industry if they want to, indicating a lack of free will. Even in prostitution, the structure of the industry is such that the prostitutes do not control their business, third parties do. Prostitutes rely on such third parties for facilitation of business and for presumed protection from clients. ${ }^{77}$ In the instances that a prostitute is self-employed, they still have limited choices concerning clients. A prostitute working in a country with legalized or regulated prostitution may be able theoretically to turn down a potential client, but they must accept a certain percentage of them in order to either earn a living or to submit to their pimp.

According to a definition of "decent work" the ILO, which is generally favorable to the sex industry as a legitimate professional choice, prostitution cannot be considered decent work. The definition is as follows:

Decent work sums up the aspirations of people in their working lives. It involves opportunities for work that is productive and delivers a fair income, security in the workplace and social protection for families, better prospects for personal development and social integration, freedom for people to express their concerns, organize and participate in the decisions that affect their lives and equality of opportunity and treatment for all women and men. ${ }^{78}$

The reason that this definition undermines the notion of "sex work" as decent work is simple. First, it is doubtful that anyone aspires to be a prostitute and far more likely that they became a victim of circumstance. Second, there is not workplace or social protection for prostitutes, even in countries where the sex industry is supposedly controlled and

\footnotetext{
${ }^{76}$ Strauss, 139.

${ }_{77}$ Max Waltman, "Sweden's prohibition of purchase of sex: The law's reasons, impact, and potential," Women's Studies International Forum 34, 5, (September -October 2011): 559-474; 450.

${ }_{78}$ International Labour Organization, "Decent Work," International Labour Organization, 2013. http://www.ilo.org/global/topics/decent-work/lang--en/index.htm (accessed April 04, 2013).
} 
regulated. In law this may be the case, but not in practice. ${ }^{79}$ Third, social integration of those in the sex industry is not realized; "sex workers" are instead stigmatized. Fourth, prostitutes are often abused and mistreated, even in countries with legalization and regulation. Finally, work in the sex industry is "not a job like any other." There are special circumstances which the regulated sex industry alone encounters. These have caused considerable problems in countries with a regulated industry.

For example, in Germany "welfare officers can penalize men and women who refuse 'reasonable' job offers." Though it is not the case, it would be logical that "establishing prostitution as legitimate work would imply that welfare recipients risk to lose their benefits if they refuse sex work." ${ }^{80}$ There are additional regulations that cannot be required of prostitutes, such as the legal inability to discriminate among and turn down particular clients. ${ }^{81}$ This has created a situation where normal standards of employee behavior cannot be enforced while the social benefits of an employed status are still expected ${ }^{82}$ Such issues cause problems with implementation of sex industry regulation and social assistance to prostitutes, resulting in ineffective laws that do not provide decent work for those in the sex industry.

The argument that "sex work" can be a fulfilling and chosen profession is weak. In a human rights context prostitution does not coincide with the basic goals of a dignified, meaningful, and safe life for all people. This cannot be guaranteed in the case of the sex

\footnotetext{
${ }^{79}$ Isabel Crowhurst, Joyce Outshoorn, and May-Len Skilbrei, "Introduction: Prostitution Policies in Europe." Sexuality Research and Social Policy 9, 3 (September 2012): 187-191; 189.

${ }^{80}$ Rebecca Pates, "Liberal Laws Juxtaposed with Rigid Control: an Analysis of the Logics of Governing Sex Work in Germany," Sexuality Research and Social Policy 9, 3 (September 2012): 212-222; 212.

${ }^{81} \mathrm{lbid}$.

82 Ibid.
} 
industry, which is inherently contrary to the goals of human rights concepts. ${ }^{83}$ In any case, it has been demonstrated that the sex industry harms those working in it. Even if one of every ten people in the industry freely chose to provide sexual services, it does not mitigate the suffering of the others. Whether the sex industry does contribute to trafficking or not, there should be some reasonable consensus on the damage inflicted on those in prostitution.

If the question of what constitutes free and unfree choice is not answered in a clear and thorough manner, the consequence is a legal loophole for criminals and denied justice for victims that do not meet the specified legal definition. International organizations are relatively vague in reviewing the topic. The ILO definition of "decent work" does not firmly or clearly define its subject in a sense that would be valuable for the creation of national or international laws. It is useless in practice; an excellent ideal but lacking pragmatism. This matches the general confusion on the topic, as discussed by Strauss, who adds that this may be due in part to the relatively recent focus on unfree labor:

What is important to note is that the widespread recognition that unfreedom is a feature of labour markets in the 'advanced capitalist' economies is relatively recent, and that it extends beyond sectors that have traditionally garnered the greatest attention, such as agriculture. Thus, political and institutional responses, and academic research programmes in fields other than history and development studies, are also relatively recent phenomena. Attention from organisations such as the International Labour Organisation (ILO) has focused on definitions, responses and data gathering; what is emerging is a set of contested conceptual and regulatory approaches that articulate with one another in a variety of ways at different scales. ${ }^{84}$ The primary problem with the Marxist approach is that it fails to fully recognize gender issues in a practical way. Therefore, Marxist theory is an important perspective for this

\footnotetext{
${ }^{83}$ igma Huda, "Prostitution: A Profitable Form of Trafficking and the Mechanisms to Counter It," Pakistan Journal of Women's Studies: Alam-e-Niswan 16, (2009):25-254; 238.

${ }^{84}$ Strauss, 139.
} 
thesis, but it is not the only one, as it would lead to an incomplete understanding of the topics at hand.

In the gap left by classical Marxism, Feminist Marxism lends useful theory for working with human trafficking, specifically recognizing the economic status of women, who may be more at risk as trafficking victims. In this theory women are treated as second class citizens who take lower-paying jobs and then have the double burden of household work which may or may not include taking care of children. ${ }^{85}$ They work much more than men but much of their work is unpaid. Feminist Marxism has also highlighted the commodification of women's bodies for the pleasure of a male consumer. ${ }^{86}$ Prostitution was a topic that was recognized as a subject worthy of attention from communist writers, who indicated that the laws criminalizing prostitutes put already economically marginalized women seeking to supplement their low incomes in an even more precarious situation. If they were caught and registered, such women were usually recognized as being unworthy candidates for other, legitimate jobs. ${ }^{87}$ Women are disproportionately affected by trafficking in large part because of their lower economic, social, and educational status and lack of opportunities in many countries. In regards to trafficking for sexual exploitation, commodification of (primarily) women's bodies for purchase by men is an important subject. Women are less able to commodify their own labor. ${ }^{88}$

In many societies, women have less opportunities and access to education or to the same jobs and wages as men. In some cases where they have theoretical access to these,

\footnotetext{
${ }^{85}$ Nancy Arden McHugh, "Feminist Philosophies A-Z; Marxist Feminism," Credo Reference, 2007. http://www.credoreference.com.www.libproxy.wvu.edu/entry/edinburghfem/marxist_feminism (accessed March 14, 2013).

${ }^{86}$ McHugh.

${ }^{87}$ Pates, 217.

${ }^{88}$ Strauss, 145.
} 
they do not have practical access; gender segregation of labor forces is an important component, causing women to remain in less financially lucrative positions compared to their male counterparts. ${ }^{89}$ Women are also generally held responsible for domestic labor, including care of household and children, with emphasis on these being feminine roles that leave no room for male participation. Because of these factors, women can find themselves in an economically vulnerable state while carrying the double burden of a job and domestic life. This leads to greater risk-taking due to changes in risk assessment on an individual level. Through an increase in acceptable risk-taking due to desperation, women become easier targets for human trafficking because they are easier to mislead and ignore warning signals of potentially dangerous situations.

Like Marxist theory, Neoliberal economic theory, which prefers markets to have as little regulation as possible, is useful in attempting to understand the rationale behind exploitation. This theory would see the legalization of prostitution, lack of workplace standards, and in its most strict definition, the selling of human beings as a legitimate free market enterprise. Neoliberal theory furthermore may support and perpetuate gender inequalities, with its emphasis on "masculine" traits such as "rationality, competitiveness, and ambition" while devaluing the "feminine" traits of "altruism, love and cooperation". ${ }^{90}$

There is evidence negating the hypothesis supported by Neoliberal theory that legalization of prostitution would cause a decrease of trafficking in persons or a decrease of gendered violence. Total regulation is not feasible; many prostitutes will continue to operate unregistered and illegally. This is particularly true of those who have been trafficked due to

\footnotetext{
${ }^{89}$ Labor force segregation based upon gender is a prominent phenomenon in Estonia but not Sweden, where significant efforts to avoid such separation have been made.

${ }_{90}$ Rachel Bezner Kerr and Paul Mkandawire, "Imaginative geographies of gender and HIV/AIDS: moving beyond neoliberalism," GeoJournal 77, 4 (August 2012): 459-473; 462.
} 
the illegal nature of their recruitment. Statistics indicate that those countries with legalized prostitution have a higher number of victims of human trafficking than those which have acted to criminalize prostitution. Some prostitution legalization advocates are subscribers of the mistaken belief that most in the sex industry legitimately choose this type of work "freely". However, this is not quantifiable, and the fact is that indeed the overwhelming majority of women in prostitution lack real, true choice. They lack the skills and education that would have allowed them to enter legitimate careers and once they have entered into prostitution, they bear a social stigma which makes them undesirable as potential candidates for legitimate careers. Leaving prostitution is difficult to impossible due to a variety of factors.

Legalized prostitution makes purchasing sex less taboo and more acceptable. The industry becomes more lucrative and the demand actually increases. Supply will also increase to meet the demand, encouraging the forced recruitment of individuals for the sex industry. Although there is often a local impetus for increasing the number of domestic sex workers in prostitution, foreigners have more value due to eroticization of ethnicity or culture; buying exotic women is not difficult due to the globalized market of human trafficking. ${ }^{91}$ Trafficked sex workers under control of a pimp are more desired by sex buyers because they are available for sex acts which supposed prostitutes by choice may refuse. ${ }^{92}$ Of course, even purported "free" prostitutes may be forced to consent and not have truly free choice due to monetary needs, aggressive customers, or other option-reducing circumstances.

\footnotetext{
${ }^{91}$ Huda, 236; Carolina Johansson Wennerholm, "Crossing Borders and Building Bridges: The Baltic Region Networking Project," Gender and Development 10, 1 (March 2002): 10-19; 13.

${ }^{92}$ O'Brien, 557.
} 
People will act out of selfishness and profit-seeking, which neoliberal theory not only allows, but encourages. Even if prostitution were to be legalized and regulated, many prostitutes will not register themselves due to avoidance of burdensome taxes, social stigma, or control by pimps. ${ }^{93}$ Most of these prostitutes will be controlled by a pimp regardless of legalization due to the structure of prostitution, further complicating the definition of free will and force. Due to uneven regulation and a virtual impossibility to register and supervise all prostitutes, tax contributions from prostitutes are not a legitimate reason for legalization and regulation. This, in turn, raises the problem of re-victimization; prostitutes are not only the victims of gendered and sexual violence, but also the victims of a government that seeks to profit from their victimhood through taxation in the regulated sex industry.

Exploitation is not incompatible with neoliberal beliefs, which posit that undesirable jobs with dangerous working conditions are better than no work, in particular for the economy but also for the individual. This combines selfishness with a false sense of morality (e.g. "at least we are giving them jobs"). This rhetoric appears in the debates revolving around both sweatshops and prostitution. It has been argued, for instance, that sweatshop labor is not exploitative but instead is as beneficial to the employee as for the employer, as providing any sort of job "is a morally praiseworthy means of helping to encourage economic growth in poor areas of the world and to provide jobs that pay better and are more stable than any existing alternatives." ${ }^{94}$ Concerning prostitution, some men who purchase sexual services justify their actions by casting themselves as a charitable person who, through paying the prostitute, helps support her and her needy family.

\footnotetext{
${ }^{93}$ Swedish Institute, "Selected extracts of the Swedish government report SOU 2010:49: The Ban against the Purchase of Sexual Services. An evaluation 1999-2008," Policy Evaluation, Swedish Institute, Stockholm, 56.

${ }^{94}$ Jeremy Snyder, "Exploitation and Sweatshop Labor: Perspectives and Issues," Business Ethics Quarterly 20, 2 (April 2010): 187-213; 188. Please refer to this article for an example of Snyder's neoliberal viewpoint, which attempts to validate work exploitation in developing economies.
} 
There is also a rejection of Enlightenment ideas, such as Kant's Formula of Humanity, which suggests that one must not use another person as a means to acquire a goal (in this case material wealth) but rather as an end in itself. Treating another person as a means "is typically understood to entail negative duties that proscribe against interfering with others' autonomy," but a neoliberal viewpoint such as Jeremy Snyder's argues that other factors such as "physical and psychological needs" are as likely to interfere with autonomy as a forceful or coercive employer. ${ }^{95}$ In other words, a neoliberal opinion could imply that it is not the sweatshop employer who exploits the employee but rather the employee's own needs. This is an important interpretation to consider in regards to exploitation because it essentially rejects the necessity of meaningful employment.

Meaningful employment must include some level of professional autonomy for the employee and the further development of such, as well as enough pay to ensure that employees may afford both basic food and other needs. ${ }^{96}$ It follows that realistically, sweatshop labor is not meaningful employment because it treats the workers as a means rather than as an end in the support of a capitalist goal of earning as much profit as possible, disregarding the quality of life for the workers involved in creating the goods ${ }^{97}$ This logic can also be applied to all types of forced, coerced, or unfree labor, such as prostitution. Because neoliberalism places profit above the human cost and values "masculine" traits, it can be used in an attempt to rationalize support for prostitution legalization. Legalized prostitution is a driving force for an increase in human trafficking for the purpose of sexual exploitation.

\footnotetext{
${ }^{95}$ Ibid, 196.

${ }^{96}$ Ibid, 197; Norman Bowie, Business Ethics: A Kantian Perspective," Wiley-Blackwell (1999), 70-71.

${ }^{97}$ Huda, 236.
} 
Research for this thesis has found there is a nexus between gender, economy, power, and sexual exploitation concerning human trafficking for sexual exploitation. Due to these intersecting factors, it is practical to use a combination of theories which examine these influences independently to enable a more full assessment of human trafficking for the purpose of sexual exploitation. Marxism, with its critique of social classes, allows an understanding of the concept of exploitation. Marxist Feminism fills the gaps of classical Marxism by recognizing the double burden of women at home and work. This reformulates the understanding of social classes to include women as existing in a lower class than men and having fewer economic opportunities, making women at a higher risk of trafficking for sexual exploitation.

Legalized or regulated prostitution are driving forces for the demand of trafficked persons to exploit in the sex industry. Because neoliberalism is pro-profit regardless of the human cost, it supports prostitution legalization. Feminist viewpoints are also particularly relevant in debates over prostitution. One view is that prostitution is a legitimate professional choice made by consenting individuals with self-autonomy. Generally individuals possessing this opinion are supportive of a legalized and regulated sex industry which they claim would allow sex workers to continue their chosen profession while affording them additional legitimacy in society and protection from abusive sex purchasers. The opposing feminist view is that prostitution is always forced, whether through the physical violence of a sex purchaser or through the economic situation of a prostituted person. Individuals of this opinion favor criminalizing prostitution or the purchase of sexual services. All of these theoretical perspectives combine to provide a more full assessment of human trafficking for sexual exploitation. 


\section{SWEDEN's ANTI-HUMAN TRAFFICKING LEGISLATION}

Sweden is a welfare state which guarantees a standard of living and social rights in return for taxes to support the system monetarily. Social discussion on the need for social services began in the 1880 s and was inspired "by the important social problems in the late $19^{\text {th }}$ century." ${ }^{" 8}$ As in other parts of Europe, these problems included "poverty, emigration, social and economic security on one side, and urbanization, industrialization and the introduction of capitalistic wage labour on the other. ${ }^{99}$ Poverty was the foremost topic in Swedish social policy until the 1950 s. ${ }^{100}$ Social insurance systems were created, aimed at men as the wage earner of their families, while women were given support in their roles as mothers. ${ }^{101}$ Young, unmarried women were accepted in the workforce, but "after marriage and/or the arrival of the first child, the women were supposed to give priority to housework and childcare." ${ }^{102}$ This attitude was prevalent during the 1930s, when Sweden experienced both economic and population crises. ${ }^{103}$ In response, a new family policy was introduced which, "strengthened the male breadwinner model and made it easier for the working husband to support his wife and children". ${ }^{104}$ This included child care assistance for mothers who were sick. ${ }^{105}$ Women were given suffrage in $1921 .{ }^{106}$

\footnotetext{
${ }^{98}$ Urban Lundberg and Klas Amark, "Social Rights and Social Security: The Swedish Welfare State 1900-2000," Scandinavian Journal of History 26, 3 (2010): 157-176; 157.

${ }^{99}$ Ibid.

${ }^{100}$ Ibid, 159.

${ }^{101}$ Ibid.

102 Ibid.

${ }^{103}$ Ibid, 160; Sondra R. Herman, “Children, Feminism, and Power: Alva Myrdal and Swedish Reform,” Journal of Women's History 4, 2 (1992): 82-112; 83-84.

${ }^{104}$ Lundberg and Amark, 163.

105 Ibid.

${ }^{106}$ Herman, 84
} 
World War II left Sweden, which had not been devastated as other countries had, "in a comparatively advantageous economic situation." ${ }^{107}$ Sweden was the third-richest country in the world by $1970 .{ }^{108}$ In 1974 , maternity leave was replaced with a parental leave system, which could also be used by fathers. ${ }^{109}$ As rights for women have increased and they have joined the workforce in greater numbers, state support for mothers has also been enlarged. ${ }^{110}$ This is one of the key underpinnings of Swedish gender equality measures making it possible for couples to have children and not be forced to sacrifice their careers, thus promoting financial independence. Another crucial factor in Sweden's gender equality approach is access to education, which allows men and women equal opportunity.

Violence against women has been taken very seriously in Sweden, leading to the criminalization of the purchase of sexual services; prostitution is viewed a gendered violence. Sweden has emerged as an example of progressive legal action in response to human trafficking for sexual purposes by criminalizing the purchase of sexual services. ${ }^{111} \mathrm{~A}$ part of the Act on Violence Against Women, the law is inspired by feminist ideology, years of campaigning, and multiple government inquiries regarding prostitution. ${ }^{12}$ It is accompanied by laws against pandering and providing spaces for prostitution activities. ${ }^{113} \mathrm{It}$ is based upon the concept that sex purchase is inherently an act of violence against the

\footnotetext{
107 Ibid, 163.

108 Ibid.

109 Ibid, 165.

${ }^{110}$ Lundberg and Amark, 170-171.

${ }^{111}$ Ekberg, 1191. This law became effective January $1^{\text {st }}, 1999$.

112 Ibid.; Swedish Institute, "Selected Extracts of the Swedish Government Report SOU 2010:49: The Ban Against the Purchase of Sexual Services. An Evaluation 1999-2008," Policy Evaluation, Stockholm (2010). For a list of relevant Swedish legislation and inquiries, please refer to: Max Waltman, "Sweden's Prohibition of Purchase of Sex: The Law's Reasons, Impact, and Potential," Women's Studies International Forum 34, 5 (2011): 449-474 and Nadejda K. Marinova and Patrick James, "The Tragedy of Human Trafficking: Competing Theories and European Evidence," Foreign Policy Analysis (July 2012): 231-253.

${ }^{113}$ Susanne Dodillet and Petra Östergren, "The Swedish Sex Purchase Act: Claimed Success and Documented Effects," presented at the workshop "Decriminalizing Prostitution and Beyond: Practical Experiences and Challenges", The Hague (March 3-4 2011), 3-4.
} 
prostituted person. The most revolutionary part of the law lies in its approach to supply and demand. Rather than outlawing the act of prostitution, the purchase of sex was targeted. Prostitutes were blameless in their own exploitation whereas sex purchasers were criminalized. The ban was preceded by a great deal of debate over the ideology and efficacy of such a law, which continued into the years immediately following its establishment. There is compelling evidence, however, that the law is highly effective in relation to human trafficking for sexual exploitation.

The set of laws targeting human trafficking originally enacted in Sweden focused primarily on trafficking for the purpose of sexual exploitation. Within a few years the focus turned to trafficking for other purposes. Legislation active from July 1, 2002 criminalized trafficking for sexual exploitation ${ }^{114}$, which carried a minimum of 2 years and a maximum of 10 years in prison. ${ }^{115}$ In March 2004, a proposal to amend the law was recommended and in July 2004 it was modified to include "all forms of trafficking in persons, including trafficking within national borders and trafficking for other forms of exploitation, such as forced labor and slavery." 116 The Act Prohibiting the Purchase of Sexual Services was developed as part of a bill addressing violence against women and was based upon the findings of the 1993 Prostitution Inquiry and the Final Report of the Commission on Violence Against Women (1995). ${ }^{117}$ According to the Swedish Penal Code Chapter $6 \S 11$,

\footnotetext{
${ }^{114}$ Victims must have been coerced or deceived (unless under the age of 18 ) and transported across international border.

${ }^{115}$ Kajsa Wahlberg, "Global Problems-Local and Regional solutions, "Speech by Kajsa Wahlberg, Swedish National Rapporteur on Trafficking in Human Beings at the Conference on Trafficking in Human Beings and Prostitution (Copenhagen: Women's Council in Denmark, March 23, 2012), 1.

${ }^{116}$ Ekberg, 1113; Marinova and James, 238; Swedish National Police Board, "Trafficking in human beings for sexual and other purposes," Situation report (Lägesrapport), PVS Information Unit, Swedish National Police Board, 2011, 32.

${ }^{117}$ Swedish Institute, 6.
} 
the obtainment of sexual services in exchange for any type of compensation (monetary, narcotics, etc.) is a criminal activity subject to punishment of fines or imprisonment. ${ }^{118}$

The procuring law is covered by $6 \S 12$ of the Penal Code, stating that, "Anyone who encourages or improperly economically exploits a person having casual sexual relations in return for payment is sentenced for procuring to a term of imprisonment of a maximum of four years". ${ }^{119}$

Chapter $4 \S 1$ (a) of the Penal Code, which concerns trafficking, states that:

A person who, in cases other than those stated in $\S 1$, by means of unlawful coercion, deceit, exploitation of a person's vulnerable situation or by any other such improper means, recruits, transports, transfers, houses or receives another person, and in so doing takes control of that person in order for the person to be exploited for sexual purposes, removal of organs, active military service, forced work or for some other purpose in a situation involving distress for the victim, will be sentenced to imprisonment for human trafficking for a period of a minimum of two and a maximum of ten years. ${ }^{120}$

This provision of the Swedish penal code is generally strong, being backed with a significant penalty and applies to all forms of trafficking. In addition, Sweden has an alien's act which guarantees that a temporary residence permit may be granted for a maximum of six months' time, "at the request of the enquiry leader to an alien who has been living here, if this is required in order for a preliminary investigation or main hearing to be held in the criminal case." ${ }^{121}$ This is applicable in cases of human trafficking in particular, where there is the possibility for the victims to be deported prior to being able to give testimony, rendering the

\footnotetext{
${ }^{118}$ Ibid, 6; Swedish National Police Board, 23.

${ }^{119}$ Swedish National Police Board, 32.

${ }^{120}$ Ibid.

${ }^{121} \mathrm{Ibid}, 33$.
} 
case very difficult to prosecute. This has been a significant difficulty for human trafficking cases in many countries in which there is not a similar act.

The government of Sweden has also been active in the creation and support of initiatives to assist sexually exploited persons as well as the establishment of education programs. Between 2004 and 2006, the government financed the police with funds totaling 30 million Kroner (3.9 million USD) to combat human trafficking. ${ }^{122}$ Inter-organizational cooperation has been encouraged through various anti-trafficking initiatives and funding. ${ }^{123}$ From July 2008 to 2012, the Swedish government invested a total sum of 213 million Kroner (30.3 million USD) to support a program developed to foster "greater protection for people at risk, preventive work, higher standards and efficiency in the justice system, increased awareness and national and international cooperation." ${ }^{124}$

The gendered approach to combating human trafficking in Sweden is clearly evident in the legislative acts themselves, the attitudes and ideas expressed by Swedish officials, and the dialogue that framed the institution of the law banning the purchase of sex as a law to prevent human trafficking. There is a focus on the exploitation of women for the gratification of men. Furthermore it is logical that the sex industry contributes to human trafficking in the sense that it increases trafficking of persons for sexual exploitation. To remove discussion of prostitution from the anti-trafficking debate and legislation is nearly impossible; some of the principles of the Palermo protocol and the Swedish legislation are based in Radical Feminist ideology (in the manner of Gunilla Ekberg). The pertinent concept is that the sex industry is created for men and is both supported by and perpetuates cultured gender norms, which also cultivate oppressive power relations of men over

\footnotetext{
${ }^{122}$ Marinova and James, 238.

${ }^{123}$ Refer to Marinova and James, 238 for more detailed information.

${ }^{124}$ Ibid, 237-238.
} 
women. ${ }^{125}$ Because the sex industry is a destination for a significant percentage of persons who have been trafficked, targeting the sex trade was seen as a viable solution against human trafficking for the purpose of sexual exploitation.

Globally, an estimated nine to ten percent of men purchased sex within a year of being surveyed in 2006, though in Europe the average was about three percent. ${ }^{126}$ Statistics from around the world indicate that there are variations in the number of men who have purchased sex, which is an outcome at least partially dependent upon culture. Purchasing sex is perceived and tolerated differently by each culture and there is not a unified culture of masculinity or one norm connecting the world's males. Reasons for sex purchase are likely just as complex and dependent upon a wide variety of factors. Some of the noted reasons range from entertainment to part of a masculine social ritual, desire for sex with young persons, desire for sex acts which they believe an intimate partner would object to, desire for sex with an "exotic" person, and reinforcement of feelings of control or power. ${ }^{127}$ As an entertainment activity, some men form social groups and purchase sex together, performing a public act that increases their vision of a masculine image. ${ }^{128}$ Concerning a desire for youthful sex workers, "over three-quarters expressed a preference for women aged 25 or under and 22 per cent preferred those aged 18 or below". ${ }^{129}$ This focus on the age of the woman or girl is also related to ideas of male virility and female attractiveness, whereas youth in women is desirable and age or experience in men is preferred.

\footnotetext{
${ }^{125}$ Ricardo and Barker, 4, 34.

${ }^{126}$ M. Carael, E. Slaymaker, R. Lyerla, and S. Sarkar, "Clients of sex workers in different regions of the world: hard to count," Sexually Transmitted Infections 82 (June 2006): ii26-ii33; ii26, ii29; Ricardo and Barker, 12.

${ }^{127}$ Ricardo and Barker.

${ }^{128}$ Katri Eespere, "The hidden side of prostitution: sex buyers speak," Research Report, Social Policy Information and Analysis Department, Ministry of Social Affairs of the Republic of Estonia, (Tallinn: Ministry of Social Affairs of the Republic of Estonia; 2007); 17, 23-24; Ricardo and Barker, 34.

${ }^{129}$ Ricardo and Barker, 13.
} 
According to the Swedish Radical Feminist ideology backing the ban on the purchase of sexual services, prostitution is an inherently forced industry which degrades the persons of those forced to service clients. In the vast majority of cases, the sex purchasers are men and the prostituted person is a woman. ${ }^{130}$ The nature of the industry caters to men and their desires, not women's. ${ }^{131}$ Men who believe in the supremacy of men and the submissiveness of women are statistically more likely to purchase sex. ${ }^{132}$ In essence, though the service being sold seems fairly straightforward - sex - it is actually part of a complex power dynamic. The majority of men purchasing sex are married or cohabiting, a fact that has rendered the "biological need" theory false. ${ }^{133}$ These men do not lack an intimate partner with whom to have sex, which supports the theory that paid sex is not a matter of otherwise repressed sexual activity, but rather one related to power.

Reinforcement of control or power as a common motivator for purchase of sexual services finds some men buying sex "to experience certain models of gender relations and submissive femininities and reinforce their own feelings of masculinity and power and control in relationships." ${ }^{134}$ Some men also seek out victims of human trafficking to exploit in prostitution because they view them "as objects or commodities who could be bought and temporarily possessed by the client." ${ }^{" 135}$ Malleability in prostitutes is an important pull factor as men are seeking a feeling of power and control. ${ }^{136}$ Through prostitution, "two forms of

\footnotetext{
${ }^{130}$ There is a possible blind spot here, however, as research has been mostly based on the "traditional" view of women being prostitutes and men being sex purchasers, without investigating. thoroughly prostituted men.

131 Routhier, 11; Ricardo and Barker, 4.

132 Ricardo and Barker, 34.

133 Ekberg, 1194.

134 Ricardo and Barker, 13.

135 Ibid, 15.

${ }^{136}$ Huda, 247.
} 
social power (sex and money)," are combined in a single interaction. ${ }^{137}$ The typical sex purchaser is not lonely and seeking to fulfill "a biological urge". Rather, "buyers have money, stability, education and power" 138 Prostitution acts to "reaffirm the dominant social status of men over the subordinated social status of women." ${ }^{139}$ Sexualized racism is another element of power and control. Some sex purchasers "actively seek" prostituted members of another "race, nationality, caste, and colour," in order to exploit the already uneven balance of social power. ${ }^{140}$ Sex purchasers are rarely "men for whom paid sex is the only possibility for sexual intercourse." ${ }^{141}$

The sex industry further exploits already victimized people. Economic difficulties are common among both those in the sex industry and those trafficked for purposes other than sexual exploitation. These people weigh risks differently than those with stable economic situations, making them more vulnerable and therefore also more susceptible to exploitation. There is a general pattern in trafficking flows pertaining to areas that have high concentrations of refugees, are experiencing war, or have entered a period of economic instability, all of which are more prominently represented by the victims of human trafficking. Countries where oppressive norms are imposed upon women and their rights are limited are also more prominently represented. ${ }^{142}$ These women may be restricted from the job markets of their home countries, yet find the need to support themselves or their families. ${ }^{143}$ To fulfill this obligation, they seek employment abroad, possibly agreeing to

\footnotetext{
${ }^{137}$ Ibid, 246.

${ }^{138}$ Ministry of Industry, Employment, and Communications, "Prostitution and Trafficking in Human Beings," Stockholm (April 2005); Eespere, 4.

${ }^{139}$ Huda, 246.

140 Ibid.

${ }^{141}$ Eespere, 15. In this study, there were no such men.

${ }^{142}$ Swedish National Police Board, 10.

143 Ibid.
} 
provide sexual services. ${ }^{144}$ Many women that are trafficked into and exploited in the sex industry are conscious of the fact that they will be providing sexual services for payment. Many were previously involved in prostitution. However, the terms they are presented and to which they agreed are usually significantly different than those which are actually experienced, including, "their living conditions, financial arrangements, the abuse and degree of personal freedom." ${ }^{145}$

There is pervasive psychological, physical, and sexual abuse. The people who are exploited in the sex industry statistically display a tendency to have psychological problems prior to their involvement in prostitution, usually stemming from a past of abuse or neglect. There is a connection between childhood abuse or sexual abuse and entrance into the sex industry. The Swedish Institute notes in its Progress Report that "a strong link between exposure to sexual abuse and providing sex for money" exists. ${ }^{146}$ Past sexual abuse, "problematic relationships with their parents," difficulties in school, a desire for "acknowledgement from men," and financial desperation are all factors that can easily be exploited. ${ }^{147}$ A significant number of women in the sex industry have experienced sexual abuse during their childhood - anywhere between 65 and 90 percent. ${ }^{148}$ The Swedish National Board of Health and Welfare has reported that the majority of prostituted persons were initially abused in their early- to mid-teens. ${ }^{149}$

\footnotetext{
144 Ibid.

145 Ibid.

${ }^{146}$ Swedish Institute, 25.

${ }^{147}$ Ulla-Carin Hedin and Sven Axel Månsson, "The Importance of Supportive Relationships Among Women Leaving Prostitution," Journal of Trauma Practice (July 1, 2002): 223-237; 228; Iris Pettai, Helve Kase, and Ivi Proos, "Prostitution in Estonia: a Survey of the Situation of Women Involved in Prostitution. Results of a Sociological Study," (Tallinn: Eesti Avatud Ühiskonna Instituut/ Estonian Institute for Open Society, 2006), 9. Swedish National Police Board 2011,10.

148 Levy, 80; Routhier , 12.

${ }^{149}$ Swedish Institute, 26.
} 
Prostituted women also experience violence after entering the industry. Research into rates of prostituted individuals' experienced violence (in Sweden) indicated that 60 to 93.5 percent had suffered abuse "perpetrated by customers, partners, and pimps". ${ }^{150}$ Research on 475 prostituted individuals found that, two-thirds had post-traumatic stress disorder and displayed symptoms such as "emotional numbness, recurrent nightmares, and flashbacks among other things." ${ }^{151}$ Post-traumatic stress disorder is commonly cited as a consequence of both the sex industry and trafficking in persons for purposes other than sexual exploitation. ${ }^{152}$ This is voiced in more visceral terms by Ekberg, who says that because they have been "subjected to sexual torture in the guise of particular sexual practices such as sadomasochism, systematically humiliated, sexually harassed, threatened, raped, beaten, and sometimes kidnapped," prostituted persons "suffer psychological injuries similar to war veterans and survivors of torture, such as flashbacks, anxiety, depression, sleep disturbances, and stress." ${ }^{153}$ After such abuses, "long-term psychological support and medical treatment" are necessary. ${ }^{154}$ A survey of Swedish youth determined that 1.7 percent of respondents "had accepted remuneration for a sexual service on at least one occasion."155 Among this group, the "proportion of those who said they had problems with social integration, money, physical and mental health, low self-esteem, and alcohol and drug use

\footnotetext{
150 Jolanda Sallmann, "Living With Stigma: Women's Experiences of Prostitution and Substance Use," Affilia 25, 2 (2010): 146-159; 147-48; Hedin and Månsson, 232, 234.

151 Levy, 180; Routhier, 12.

152 Ekberg, 1211; Hedin and Månsson, 232-233; Wennerholm , 14.

153 Ekberg, 1211.

${ }^{154}$ Swedish National Police Board, 10.

${ }^{155}$ Emma Stenberg Ribeiro,." Human Trafficking and Prostitution from a Swedish Perspective," County Administrative Board of Stockholm; National Task Force against prostitution and human trafficking (NMT), 2011, 39.
} 
was much higher" than the proportion of those suffering from the same problems and who had not sold sex. ${ }^{156}$

The consequences of working in the sex industry are substantial. Prostitution also causes relationship, intimacy, and sexual problems. In 70 percent of the women studied by Hedin and Månsson, there was a reported inability to fully function in sexual relationships not related to prostitution. ${ }^{157}$ They succinctly explain the causes of this phenomenon, saying: In order to protect their psychological integrity, and defend themselves against the customer's violation, women learn to dissociate so that they do not experience physical and emotional pain. But a psychological price is paid for this emergency protection. After the breakaway, it is difficult for women to do away with their body armor and to feel pleasure, especially sexual pleasure ${ }^{158}$.

These findings were supported by Høigård and Finstad's 1986 study, in which, "interviewees reported difficulty in feeling desire or pleasure. They could not cope with sexual relationships outside of prostitution, experiencing them as dull and disgusting."159 This idea is reiterated by a former prostitute who said that after exploitation there is a shift of perception, causing one to see all types of relationships as potentially exploitative; placing trust in others is unnatural and inconceivable. ${ }^{160}$

Any attempt to claim that the sex industry, "filled with female victims of abuse, violation, poverty, and violence," is not harmful to women is observably false. ${ }^{161}$ Prostitutes become desensitized to this violence and come to expect this as part of their daily lives. ${ }^{162}$ The violence and exploitation also permanently alters persons who have been prostituted. In

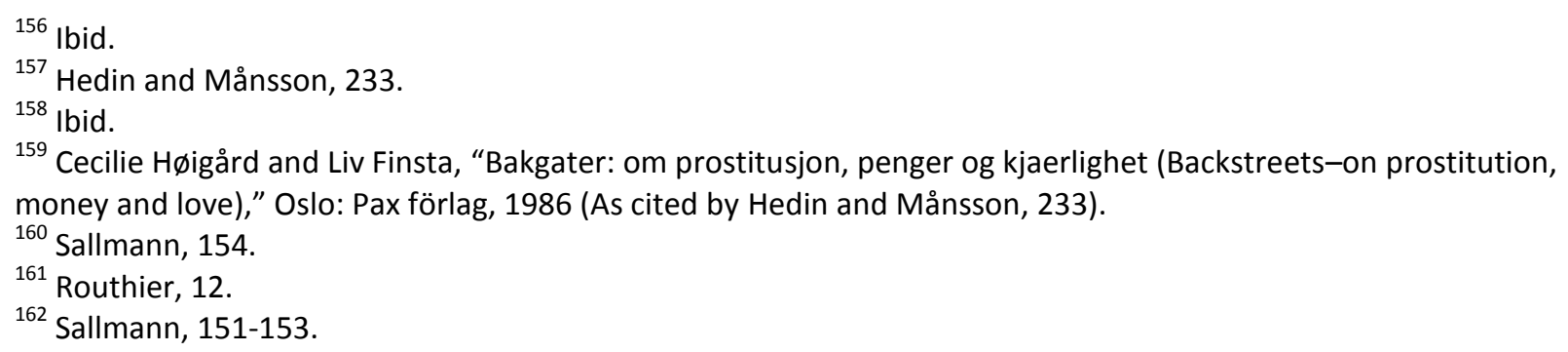


the Netherlands an evaluation of prostitutes found that the prostitutes considered their wellbeing to have deteriorated between the years 2001 and 2006, with an increase in anxiety issues and drug use. ${ }^{163}$ A study conducted in Nepal interviewing persons trafficked for the purpose of sexual exploitation in the commercial sex industry found pervasive mental health issues among victims which included a 100 percent rate of suffering from depression. ${ }^{164} \mathrm{~A}$ further 97.7 percent suffered from anxiety, 29.6 percent experienced post-traumatic stress disorder, and 29.6 percent were HIV positive. ${ }^{165}$ This data was contrasted with that of human trafficking victims for purposes other than sexual exploitation. ${ }^{166}$ The findings indicated that 80.8 percent of trafficking victims for other purposes experienced depression, 7.5 percent experienced posttraumatic stress disorder, and none were HIV positive. ${ }^{167}$ There is an enormous difference in the statistics, displaying clear consequences of being forced into the sex industry.

Prostituted people not only face abusive conditions from those involved in the sex industry, but also stigma derived from their life circumstances, which causes them to be heavily discriminated against. ${ }^{168}$ Stigma directed at prostitutes comes from a wide array of people they must interact with in daily life. These can include those in law enforcement and criminal justice, healthcare services (provided they have access), potential legitimate employers, education providers (for themselves or for their children), and child welfare

\footnotetext{
${ }^{163}$ Swedish Institute, 56.

${ }^{164}$ Erin E. Tracy and Wendy Macias Konstantopoulos, "Human Trafficking: A Call for Heightened Awareness and Advocacy by Obstetrician-Gynecologists," The American College of Obstetricians and Gynecologists (Lippincott Williams \& Wilkins) 119, 5 (May 2012): 1045-1047; 1046.

165 Ibid.

${ }^{166}$ Please refer to Charts 1 and 2 in the appendix.

167 Ibid.

168 Ibid, 147-152.
} 
services to name a few. ${ }^{169}$ In Hedin and Månsson's study, interviewees expressed the difficulties they had in obtaining psychological help during their break from prostitution, which included male physicians and psychologists propositioning them as prostitutes and other staff treating them as irrational. ${ }^{170}$ They may fear that even family and friends may become judgmental. ${ }^{171} \mathrm{~A}$ woman known as L.J. said during an interview:

People just don't have respect for people that are on, um, dope or crack or a prostitute. They just don't care, you know; you're nothing, you're just a piece of garbage and, you know, I'm going to do what I wanna do type of thing to you. Um, and I guess that all comes with the territory, you know. ${ }^{172}$

Her words reflect the harsh reality for many prostitutes, that of judgment and condescension. Sallmann's research indicates that the women interviewed were not met with any sympathy from "a supportive person"; the opposite was the case in regards to both personal relationships and "institutional support systems". ${ }^{173}$ In essence, the Swedish legislation attempts to avoid this problem of blaming the exploited person for their exploitation and providing assistance in their exit from the sex industry. This recognizes a prostituted person's victimhood and lessens the possibility of victimization by the state. It allows a prostituted person to reenter mainstream society without the same level of stigma by sending a clear message that the prostituted person is the victim. Social and personal support is important for prostituted persons attempting to leave the sex industry.

Having a dependable and supportive person is extremely important and becomes crucial for prostituted people making a permanent break from prostitution. ${ }^{174}$ In many cases

\footnotetext{
169 lbid, 147-148.

170 Hedin and Månsson, 231.

171 Ibid, 233.

${ }^{172}$ Sallmann, 151-152.

173 Ibid.

${ }^{174}$ Hedin and Månsson, 234.
} 
a supportive relationship is not only unavailable due to judgment from others, but also due to internal processes of self-preservation, which make it difficult to trust anyone after being exploited, as well as the same variety of factors which led to that person's exploitation in the first place. ${ }^{175}$ Hedin and Månsson's study found that, despite formerly prostituted individuals' fears about being accepted in new surroundings, it was possible for them to "develop friendships, new roles, and social identities." ${ }^{176}$ Though some contacts "with women friends from prostitution" continued, a permanent exit from prostitution usually saw "these contacts... diminish with time and to finally come to an end." ${ }^{177}$ Formerly prostituted persons' post-breakaway relationships usually comprised of "family members and social workers or health professionals," which were cultivated with varying degrees of comfort, speed, and permanency. ${ }^{178}$

Sweden's sex purchase criminalization law has been criticized for various reasons and by various groups. Men who felt they had the right to purchase sex were less than supportive of a criminalization act, especially one that would follow them across borders. ${ }^{179}$ Criticism of the law's efficacy has focused mainly on its capability to deter possible perpetrators, the legal rights afforded to victims of sexual exploitation, and its ability to integrate into society former prostitutes in such a manner that they would be sufficiently able to provide for themselves through legitimate career choices rather than reverting back to prostitution (and without negative consequences).

Following a Special Inquiry and criticism from observers, it was suggested "that the maximum sentence for the purchase of a sexual service should be increased from six months

\footnotetext{
${ }^{175}$ Ibid; Sallmann, 154.

${ }^{176}$ Hedin and Månsson, 230-231.

${ }^{177}$ Ibid, 230.

${ }^{178}$ Ibid.

${ }^{179}$ Ekberg, 1209.
} 
to one year in prison," imbuing the law with increased penalties for its violation. ${ }^{180}$

Furthermore, it proposed "measures and financing that allow for increased access to exit program," as well as "ensuring that those who are exploited in prostitution are seen as plaintiffs in cases of the purchase of a sexual service," which would qualify them for assistance and monetary damages. ${ }^{181}$

Sweden has taken a leading and influential role in the promotion of regional and international anti-trafficking initiatives, including funding, support, and organization. ${ }^{182}$ The values that Sweden supports internationally are based on international agreements, mainly the Palermo Protocol, in combination with its own view of prostitution. ${ }^{183}$ In programs for the Baltic Sea region, Sweden is prominent, in 2003 chairing the Nordic-Baltic Task Force against human trafficking (NBTF), which includes the Nordic-Baltic Eight ( Sweden, Norway, Denmark, Iceland, Finland, Latvia, Lithuania and Estonia). ${ }^{184}$ Furthermore, Sweden is seen as a policy pioneer that deserves imitation. With the recent suggestions that the Dutch regulatory approach to prostitution and its anti-trafficking policy have been ineffective, the "Swedish Solution" becomes increasingly promising.

The attention to gender dynamics included in the Swedish Solution is also unique and warrants discussion. Swedish attitudes towards gender norms and roles are generally considered progressive compared with those of other societies. The women's movement that developed during the 1960s was important in the questioning of gender roles. The term "jämställdhet" was created, "to describe sex/gender equality. Its purpose was to visualize

\footnotetext{
${ }^{180}$ Wahlberg, 2.

181 Ibid.

182 Marinova and James, 238-239.

${ }^{183}$ Wahlberg, 1.

${ }^{184}$ Estonian Ministry of Foreign Affairs, Public Diplomacy and Media Relations Department,"Estonia to Head Nordic-Baltic Co-operation Programme," Estonian Review (December 2, 2012); Marinova and James, $238-239$.
} 
and focus on the lack of equality between the sexes." ${ }^{" 185}$ Gendered violence was under particular scrutiny in the years leading up to the institution of the law, which "was part of an Act on Violence Against Women (Kvinnofrid), which was enacted on July 1, 1998," and proceeded by "two Commissions of Inquiry, the Commission on Prostitution (1995) and the Commission on Violence against Women (1995)." ${ }^{186}$ If the official governmental position concerning prostitution is that it is a criminal act inherently displaying violence towards women, not all Swedes necessarily prescribe to this view, spurring continued debates. The point of impasse lies in the theory that it is possible for prostitution to be fully voluntary. ${ }^{187}$

Criticisms of the law banning the purchase of sex range in target from the law's efficacy to understandings of gender norms inherent in it. One criticism has been the prioritization of finding victims of prostitution or trafficking and prosecuting perpetrators effectively. The crime of sex purchase holds a "low penal value of this type of offense," making it of a lower priority to police officers with limited resources. ${ }^{188}$ Police in Gothenburg stated that their assessment of a law as successful is determined by the number of convictions and total jail time served. ${ }^{189}$ The majority of sentences end with the penalty of a fine rather than a jail sentence. ${ }^{190}$ Requiring a confession, plea deals are considered favorable to those wishing to avoid publicly embarrassing legal proceedings ${ }^{191}$ It has been suggested that the penalty for particularly egregious offenses should be made "proportionate

185 Eva-Maria Svensson and Asa Gunnarsson, "Gender Equality in the Swedish Welfare State," feminists@law 2, 1 (2012).

${ }^{186}$ Ekberg, 1191-1192; Swedish Institute, 6.

187 Swedish Institute, 5.

188 Ibid, 10.

${ }^{189}$ Waltman, 465.

${ }^{190}$ Felipe Estrada, Tove Pettersson, and David Shannon, "Crime and Criminology in Sweden," European Journal of Criminology 9, 6 (2012): 668-688; 680.

${ }^{191}$ Swedish Institute, 10. 
to the seriousness of the crime." ${ }^{192}$ The suggestion that the maximum penalty of six months imprisonment be increased has since been accepted and the penalty was increased to one year, effective July $1,2011 .{ }^{193}$

Law enforcement authorities give precedence to targeting "street prostitution and more organized forms of prostitution that are linked to procurement or human trafficking," and pay less attention to other forms of prostitution, which is mainly due to insufficient resources. ${ }^{194}$ This creates criticism of the system as not being able to target all types of prostitution effectively. Specifically, there is criticism that the criminalization of sex purchase encourages an increase in the incidence of indoor prostitution. ${ }^{195}$ However, the point made by Kajsa Wahlberg (Swedish National Rapporteur on Trafficking in Human Beings) is "that prostitution activities are not and cannot be pushed underground," due to the dependence of the operators on the providing information about available sexual services to potential sex purchasers. ${ }^{196}$ She highlights that if a sex purchaser can find advertisements for sexual services, so can the authorities. ${ }^{197}$ Furthermore, "There is no evidence that the sale of women has moved from the streets to the Internet," according to Gunilla Ekberg. ${ }^{198}$ She focuses on the tendency of "the global prostitution and pornography industry" to adapt their illicit activities to the current advancements in technology (in this case, the internet being the most prominent). ${ }^{199}$ She goes on to give strong evidence

\footnotetext{
192 Ibid, 2.

${ }^{193}$ Waltman, 465.

${ }^{194}$ Swedish Institute, 10.

${ }^{195}$ According to Melissa Farley, "Indoor prostitution includes massage parlors and saunas, brothels, strip clubs, and escort prostitution." In "Prostitution Harms Women Even if Indoors: Reply to Weitzer," Violence Against Women 11 (2005), 952.

Dodillet and Ostergren, 8-11.

${ }^{196}$ Wahlberg, 5.

${ }^{197}$ Ibid.

${ }^{198}$ Ekberg, 1194.

${ }^{199}$ Ibid.
} 
disputing the claim that the sex industry has been pushed underground and therefore became unmonitored in Sweden after the implementation of the law banning sex purchase:

The Net Sex Project at the University of Gothenburg, a research project that studies the use of the Internet for sexual purposes, concludes in its report that the number of Swedish women who are prostituted via the Internet remains stable at around 80 to 100 women, with the same women advertised on many different Web sites. The report also concludes that the use of the Internet for prostitution purposes is a consequence of the rapid development of Internet technology and not a consequence of the Swedish legislation. ${ }^{200}$

This position is also backed by the Swedish Institute's Progress Report, which studied the effects of the law from 1999-2008, and came to the conclusion that the anxiety over forcing prostitution underground was not realized in actuality ${ }^{201}$ It does not address, however, the phenomenon of prostituted persons or third parties giving phone numbers to potential sex purchasers. ${ }^{202}$ One might assume that the law enforcement might easily coordinate undercover operations by which they would obtain phone numbers, make contact with prostituted persons, and possibly locate sex purchasers and third parties.

The influence that law enforcement has in the detection of cases and how it proceeds is a concern. The fact that the majority of police officers in Sweden are male has caused some controversy. Initially there were difficulties in convincing the representatives of the police that the criminalization of the purchase of sex was enforceable. ${ }^{203}$ There were incidences of police leniency, which were noticed and acted upon in the form of educational programs. ${ }^{204}$ This action was deemed effective:

\footnotetext{
${ }^{200}$ Ibid.

${ }^{201}$ Swedish Institute, 9.

${ }^{202}$ Dodillet and Östergren, 10-11.

${ }^{203}$ Ekberg,1196.

${ }^{204}$ Ibid.
} 
One year after the program began in 2003, there was a $300 \%$ increase in arrests, believed to be the result of the investigating officers' better understanding of the reasons behind the legislation, their deeper comprehension of the conditions that make women vulnerable to becoming victims of prostitution and trafficking, and the development of better investigation methods. ${ }^{205}$

However, prostitution is not necessarily viewed by all Swedes as forced, despite the ideology behind the legislation deeming all prostitution as involuntary. This has created some bias among individual law enforcement personnel who make a distinction. ${ }^{206}$ This is especially noticeable in the treatment of domestic prostitutes contrasted with that of foreign-origin or exotic-looking prostitutes, who seem more likely to have been trafficked internationally. ${ }^{207}$ Domestic prostitutes, or those who seem of domestic origin, are less likely to stimulate intervention.

The most vocal and widespread objection to the law banning the purchase of sexual services has been over reliable statistics. In the research for this thesis, there were many sources that disputed such reliability. This is particularly true of the Swedish National Police Board's situation report for 2010, which includes detailed statistics. In 2010 there were 31 reports of human trafficking for sexual purposes filed, with three sentences for "human trafficking for sexual purposes" and one sentence for complicity. ${ }^{208}$ Five individuals were sentenced on charges of "aggravated procuring" and fourteen were sentenced on charges of "procuring of a human trafficking nature" ${ }^{209}$ In addition, "336 legal proceedings were initiated concerning the purchase of sexual services." ${ }^{210}$ There were a total of 53 reports filed by police for human trafficking for purposes other than sexual exploitation, with 5 people

\footnotetext{
${ }^{205}$ Ibid.

${ }^{206}$ Waltman, 465.

${ }^{207}$ Ibid.

${ }^{208}$ Swedish National Police Board, 8.

${ }^{209}$ Ibid.

${ }^{210}$ Ibid.
} 
sentenced. ${ }^{211}$ The same information is available in the report itemized by county and crime committed. A further number of "734 male individuals have been reported under the Law [prohibiting the purchase of sex] from January 1999 to April 2004." ${ }^{212}$ Between 1999, the year when the ban was instituted, and 2011 4,225 men have been caught in the act of purchasing sex. ${ }^{213}$

The number of trafficking victims detected is highly dependent upon the nature of the law enforcement. This includes "resources which the police put into detecting this crime and on the experience and competence that exists within the police organization," all of which are subject to variability over time.${ }^{214}$ For the years 2009 and 2010 there was a marked "increase in the number of convictions for human trafficking, procuring and the purchase of sexual services," which was the "consequence of a Government assignment during the implementation of the national action plan," which improved the techniques and proficiency of the police. ${ }^{215}$ Marinova and James state that due to fluctuations in the number of convictions and prosecutions during different periods of time, with no discernible pattern, the data "is limited and inconclusive." ${ }^{216}$ However, it is logical that the very same reasons the Swedish Institute highlighted - deviations of law enforcement qualities - are the cause. Though the information may not be a convenient gauge of the number of trafficked persons in Sweden, it is a useful in an assessment of law enforcement activities and action. Marinova and James point to a lack of data from the years leading up to 1999, before the

\footnotetext{
${ }^{211}$ Ibid, 5.

212 Ekberg, 1195.

${ }^{213}$ Wahlberg , 4.

${ }^{214}$ Swedish Institute, 4.

${ }^{215}$ Ibid, 8.

${ }^{216}$ Marinova and James, 239-240.
} 
law was enforced, rendering a complete statistical comparison impossible. ${ }^{217}$ However, it is a known fact that accurate measurement of the number of victims of human trafficking is a virtually impossible task in any circumstance, due to the illicit character of the human trafficking industry.

Handling of victims of human trafficking and the sex industry is another point of dispute for critics of the "Swedish Solution". It is suggested that trafficked persons are not supported well enough after being located and determined as victims. ${ }^{218}$ Support and eligibility for benefits are only available to prostitutes who are willing to leave the sex industry. There is also a perceived bias in aid towards victims of forced sex work compared to victims of human trafficking for other purposes. Victims of human trafficking for other purposes are not the main target of Sweden's legislation. Therefore assistance centers and resources tend to be focused on formerly sexually exploited women, rather than on victims of all forms and sexes.

In regards to the Swedish government's assistance program for those in the process of leaving prostitution, statistics regarding permanent breaks from prostitution have been provided by supporters of the ban. Of a group of 130 prostituted individuals attempting to break from the sex industry, 60 percent had left prostitution permanently. ${ }^{219}$ There are many factors to be included in the ability to successfully break from prostitution. One strength of the Swedish law is that prostitutes understand they are considered victims and therefore eligible for assistance as opposed to criminal treatment, making them more likely to establish contact with organizations providing such help. There has been strong support for

\footnotetext{
${ }^{217}$ Ibid.

${ }^{218}$ Waltman.

${ }^{219}$ Ekberg, 1204.
} 
the Swedish legislation from those formerly engaged in prostitution, as well as those attempting to break from it. ${ }^{220}$

A flaw in the judicial system has caused a considerable amount of discussion. In cases of sex purchase, the prostitute is often called on as a witness rather than as a victim of a crime, which runs counter to spirit of the Swedish legislation. ${ }^{221}$ In such cases where the crime is treated as one against public order, the prostitute is ineligible for damages awards or state support. This situation reinforces the notion of prostitution as a victimless crime, denying justice for an unrecognized victim. ${ }^{222}$ Waltman insists that compensation and aid to victims would strengthen the law and be consistent with its original intent, saying that sex buyers, being the exploiters of "the coercive circumstances that push persons into the sex industry," should pay compensation to those whom they have exploited. ${ }^{223} \mathrm{He}$ insists on the sex purchaser's liability for compensatory damages by adding that "such civil liability provides an economic opportunity to change prostituted persons' situations which the public does not have to pay for directly." 224 In a contrary opinion, the Swedish Institute said that while there is not an explicit statement in the legislation, "there is nothing to prevent a person who has been exploited in prostitution from having the status of injured party in proceedings concerning the purchase of sexual services." 225 This discrepancy between the law's intent and its practice has been recognized and noted for improvements.

In the Swedish judicial system, courts handling criminal cases have been flooded with cases awaiting trial. Given the low priority of sex purchase and some human trafficking

\footnotetext{
${ }^{220}$ Ibid.

${ }^{221}$ Waltman, 463.

${ }^{222}$ Ibid.

${ }^{223}$ Ibid.

224 Ibid.

${ }^{225}$ Swedish Institute, 12.
} 
cases among the already existing accumulated cases, they are deemed less urgent and less worth the time and effort of prosecution than a crime that incurs greater penalties. ${ }^{226}$ Inmates serving sentences for sex offenses accounted for 8 percent of the total 5400 inmates held in Swedish prisons on October $1^{\text {st }}, 2010 .^{227}$ The relatively small number of arrests and prosecutions or monetary damages awarded under the Swedish act should not be markers of failure, as the law is normative. ${ }^{228}$ The law was made to be preventative, meaning that success is found in the number of prevented infringements rather than the number committed. ${ }^{229}$ As Wahlberg said in a speech in March of 2012, "Laws are not created solely for the purpose of sending people to prison or to fine them. Laws are created because we want people to refrain from certain harmful acts." 230

Ekberg further clarifies her argument concerning prevention and prosecution, saying that "the Swedish police are to intervene before a crime is committed. However, the arrest and prosecution of the perpetrators is, of course, of equal importance." ${ }^{231}$ This unfortunately conflicts with information provided by the Swedish Institute, which says that due to attempted crimes being more difficult to prove, and therefore warrant sentences in cases of street prostitution, "the police deliberately wait until the sexual act has begun before intervening, and the offense has thus been committed in full." 232

This could be considered a structural flaw if one were to weigh convictions heavily as an efficacy indicator or an imperfection in the legislation rather than a falsification of information or a deliberately hurtful practice. It is possible that there was initially every

\footnotetext{
${ }^{226}$ Estrada, Pettersson and Shannon, 677.

227 Ibid, 682.

${ }^{228}$ Ekberg, 1209.

${ }^{229}$ Ibid, 1195; Wahlberg, 5.

${ }^{230}$ Wahlberg, 5.

${ }^{231}$ Ekberg, 1195.

${ }^{232}$ Swedish Institute, 11.
} 
intention to intervene in attempted sex purchases, but the weight of an attempted crime places it at a lower level of priority. By waiting until the sex act has been initiated, the crime is no longer attempted, but committed, and of higher priority to law enforcement. Ekberg, however makes a valid point by using the example of laws against rape and laws against financial crimes, which are also preventative. ${ }^{233}$ She says that "If we were to base the effectiveness of laws on the number of convictions in relation to the number of crimes committed," the previously mentioned laws would "have to be discarded as mostly ineffectual in stopping the flow of criminals and such crimes." 234

Through an extension of this argument that the Swedish law on sex purchase is a normative law, a low number of convictions would indeed support an argument of efficacy for the law; if there are few convictions there is success, provided that the law is indeed a deterrent and enforced. This coincides with Wahlberg's statement that "The police intervene in many cases where we assume that someone is planning on buying sexual services, and inform potential buyers that this is prohibited. Such interventions are not included in the statistics but have a direct preventative effect on the overall problem." 235 There is also deterring power of the law for "young women who are not yet in prostitution but who are runaways or soft drug abusers," and therefore more at risk to be sexually exploited. ${ }^{236}$ This sentiment is echoed by Wahlberg, who said that "If the law causes men to refrain from buying sexual services and fewer women enter into prostitution, this is a true success." ${ }^{237}$

\footnotetext{
${ }^{233}$ Ekberg, 1209.

${ }^{234}$ Ibid.

${ }^{235}$ Wahlberg, 5.

${ }^{236}$ Ekberg, 1204.

${ }^{237}$ Wahlberg, 5.
} 
In Sweden, all identified victims of human trafficking for the purpose of sexual exploitation have been female, with no incidences of male victims. ${ }^{238}$ Victims ranged in age from 13 to $45 .{ }^{239}$ Detected foreign girls and women trafficked to the Swedish sex industry, "came primarily from Eastern Europe in 2010," with special mention of Romania, Estonia, the Czech Republic, Slovakia, and Hungary. ${ }^{240}$ Other common countries of origin included Thailand and Nigeria. According to the Swedish National Police Board's 2010 Situation Report, this is a shift from the previous majorities of Estonia, Russian, and Polish nationals. ${ }^{241}$ It is believed that this shift in the victims' nationalities "can be explained by a weaker national socio-economic climate or may be the result of EU-wide political resolutions," making travel between EU member states easier. ${ }^{242}$ The increase in the number of Nigerian women represented in the Swedish sex industry may be in part due to the Norwegian ban on the purchase of sexual services, with which this upsurge coincided. ${ }^{243}$ The theory explaining a decrease in the number of trafficked Polish women is based on strong economic growth "that also benefitted women." ${ }^{244}$ Swedish victims were also detected, the notable phenomenon of "mentally impaired girls and women... [being] sexually exploited by men." 245

The majority of detected victims of human trafficking for sexual exploitation "belonged to minority groups in their homelands, had difficulties gaining employment or came from a home environment in which circumstances had been bad, involving assault,

\footnotetext{
${ }^{238}$ Swedish National Police Board, 4.

${ }^{239}$ Ibid, 9.

${ }^{240}$ Ibid, 4.

${ }^{241}$ Ibid.

${ }^{242}$ Ibid, 8.

${ }^{243}$ Ibid.

${ }^{244}$ Ibid.

${ }^{245}$ Ibid, 4.
} 
sexual abuse and social exclusion." ${ }^{246}$ Additionally, they were unable to understand or speak Swedish or have understanding of "how Swedish society functions or of any opportunities for seeking help and protection from the police, social authorities and voluntary organisations," putting them at an extreme disadvantage and rendering them entirely dependent upon their traffickers and pimps. ${ }^{247}$ Even had these trafficked persons been able to effectively communicate, it has been demonstrated that victims are distrustful of "the public authorities and are unwilling to be interviewed by the Police, or testify against their attackers." 248 Interpreters are not often trusted, as "they may come from the same background as the victim or come from the same place or country," and able to circulate information about the victim to those whom they may know. ${ }^{249}$

Traffickers and persons involved in activities supporting human trafficking themselves were from Slovakia, Romania, the Czech Republic, Sweden, Denmark, Estonia, Nigeria, Cameroon, Uganda and Iran. ${ }^{250}$ Most discovered pimps were Swedish citizens of foreign heritage and had links to organized crime in the countries of their heritage, along with some Swedish nationals. ${ }^{251}$ Perpetrators were mostly men, but some were also women. ${ }^{252}$ It is common for formerly exploited women to become exploiters themselves. ${ }^{253}$ Kajsa Wahlberg has stated that "The larger crime networks in Europe that organize trafficking in human beings for the purpose of sexual exploitation of for other purposes are

\footnotetext{
${ }^{246}$ Ibid, 9; Wahlberg, 3.

${ }^{247}$ Swedish National Police Board, 9.

${ }^{248}$ Ibid.

249 Ibid.

250 Ibid, 4.

${ }^{251}$ Ekberg, 1200.

${ }^{252}$ Swedish National Police Board, 9.

${ }^{253} \mathrm{Ibid}$.
} 
not established in Sweden." 254 The crime networks active in Sweden tend to be smaller but with active connections to countries of origin. ${ }^{255}$ This information is corroborated by the Swedish National Police Board, which stated that "The criminal groupings responsible for human trafficking crimes detected in Sweden in 2010 were on a smaller scale, but are assumed in many cases to belong to larger organised networks in the victims' countries of origin. ${ }^{256}$ Sharing the same heritage as the person they exploit put traffickers at an advantage over their victims. Such perpetrators are knowledgeable of the victims' home environments and challenges, as well as operable social mores and current situations in these locations. ${ }^{257}$ They combine this knowledge with an understanding of their adopted society. ${ }^{258}$ This knowledge is used to recruit and control the women. ${ }^{259}$

Despite criticism of the law banning the purchase of sexual services, there is evidence of its efficacy. Generally in Sweden there has been "a dramatic drop in the number of street prostitutes, johns, and recruiters of the sex industry." ${ }^{260}$ Ekberg estimated that the number of women involved in street prostitution decreased 30 to 50 percent from the years 1999 to $2004 .^{261}$ This is corroborated by the Swedish Institute's Progress Report, which estimates that the number of street prostitutes was reduced by half. ${ }^{262}$ Estimates as to the number of women prostituted in Sweden during 1999 were approximately 2,500, of which 60 percent were involved in street prostitution. ${ }^{263}$ For 2002 , the estimate was 1,500 women and by

\footnotetext{
${ }^{254}$ Wahlberg, 3.

255 Ibid.

${ }^{256}$ Swedish National Police Board, 9.

${ }^{257}$ Wahlberg, 3.

258 Ibid.

${ }^{259}$ Swedish National Police Board, 9.

260 Routhier, 15.

${ }^{261}$ Ekberg, 1193-1194.

${ }^{262}$ Swedish Institute, 7-8.

263 Ekberg, 1193.
} 
2004 , the number dramatically dropped to approximately $500 .{ }^{264}$ A weakness of these statistics exists in their count of only street prostitution, which is assumed to be half as large as indoor prostitution. ${ }^{265}$ There has, however, been no increase in prostitution since the introduction of the ban, including indoor prostitution. ${ }^{266}$ Such an increase did not materialize as feared. ${ }^{267}$ The Swedish Institute has determined that according to its assessment, the ban "has had the intended effect and is an important instrument in preventing and combating prostitution.." ${ }^{268}$ Furthermore, it "appears fairly certain that the law has had a preventative effect on heterosexual street prostitution," despite the difficulties of measurement. ${ }^{269}$ The number of Swedish johns in 1999 was an estimated 125, which decreased between 75 and 80 percent. ${ }^{270}$ According to Wahlberg, between 1996 and 2008, the number of sex purchasers dropped from 13.6 percent to 7.8 percent. ${ }^{271}$

There was a general trend of increased prostitution in neighboring countries which was not mirrored in Sweden. ${ }^{272}$ Prior to the enactment of the legislation in Sweden, the occurrence rates of street prostitution in Norway, Denmark, and Sweden's capitals were comparable. ${ }^{273}$ In 2008, Norway and Denmark experienced street prostitution rates three times higher than that of Sweden. ${ }^{274}$ When Norway followed Sweden in the legislation targeting buyers in 2009 it experienced an "immediate, dramatic reduction of street

\footnotetext{
264 Ibid, 1193-1194.

${ }^{265}$ Swedish Institute, 26.

${ }^{266}$ Ibid, 8.

${ }^{267}$ Ibid.

${ }^{268} \mathrm{Ibid}, 11$; Huda, 42.

${ }^{269}$ Estrada, Pettersson and Shannon, 671.

${ }^{270}$ Ekberg, 1193-1194.

${ }^{271}$ Wahlberg, 4.

${ }^{272}$ Swedish Institute, 8-9.

${ }^{273}$ Ibid.

${ }^{274}$ Ibid.
} 
prostitution" ${ }^{275}$ Neighboring countries without similar legislation banning sex purchase also report higher levels of trafficking compared to Sweden. ${ }^{276}$ In 2004 estimates by the National Criminal Investigation Department ranged between 400 and 600 individuals trafficked into Sweden from the primary countries of Estonia, Lithuania, and Russia. ${ }^{277}$ Denmark was estimated to have a total of 5,500 to 7,800 individuals active in prostitution. ${ }^{278}$ There were also reports of a "dramatic increase" in the number of foreign prostitutes in the Danish sex industry, indicating a warning sign of international human trafficking. ${ }^{279}$ In Finland, estimates of 10,000 to 15,000 women (primarily originating from the three "Baltic states" and Russia) in prostitution were reported. ${ }^{280}$ There are reports by abolitionist organizations that 80 percent of the prostitutes of the Dutch sex industry are victims of human trafficking. ${ }^{281}$

The logic explaining Sweden's relative low number of trafficked persons in the sex industry is ascribed to the key difference of the ban on sexual service purchase. ${ }^{282}$ It is also possible that there has been a reduction in human trafficking due to increased public knowledge and governmental awareness. When human trafficking became a "legislative priority," public discourse on the topic increased. ${ }^{283}$ The law banning the purchase of sexual services is quite popular among Swedes, indicating that the population finds it effective. ${ }^{284}$ State action, "whether in the form of legislation, police enforcement, or both," has been

\footnotetext{
275 Ibid.

${ }^{276}$ Ibid, 3.

277 Ekberg, 1199-1200.

278 Ibid.

${ }^{279}$ Swedish Institute, 8.

280 Ekberg, 1199-1200.

${ }^{281}$ O'Brien, 553.

${ }^{282}$ Swedish Institute, 8-9.

${ }^{283}$ Marinova and James, 239.

284 Ibid.
} 
identified by some as the key factor in the prevention and cessation of human trafficking. ${ }^{285}$ The Swedish legislation is effective and worth being adopted by other countries.

285 Ibid. 


\section{ESTONIA}

The connection between Sweden and Estonia regarding human trafficking is based upon their shared geographical location on the Baltic Sea and mutual history. Travel between these two countries is uncomplicated. Sweden once controlled the territory of Estonia, which has also been governed or occupied by Danes, Germans, Russians, and Soviets. Additionally, Estonia has recently made attempts to change the image of the country from regionally and culturally post-Soviet to Scandinavian. This move could possibly be made with the alignment of state legislation to match the attitudes of the region Estonia wishes to join.

After approximately twenty-five years (1202-1227) years of struggle against foreign invasion, the Estonian territory was occupied by the Teutonic Knights and Danes in $1227 .{ }^{286}$ The Teutonic Knights held Southern Estonia while Northern Estonia was ruled by the Danes. ${ }^{287}$ Following rebellion which they were unable to contain in 1343 , the Danes sold their holdings in Northern Estonia to the Teutonic Knights. ${ }^{288}$ Under both Danish and Teutonic rule, serfdom was gradually introduced to the previously "independent landowning" Estonians. ${ }^{289}$ Initially, Estonians remained nominally owners of their land and property," but were charged for "gradually increasing taxes and obligations," including "surrender of one-tenth of the crop, road, castle, and church-building obligations [and] military service during war" ${ }^{290}$ The establishment of fiefdoms and continued loss of

\footnotetext{
${ }^{286}$ Viilabald Raud, Estonia - A Reference Book (New York: Nordic Press, 1953), 14-17.

287 Ibid, 17.

${ }^{288}$ Ibid, 17-18.

${ }^{289} \mathrm{Ibid}, 18$.
} 
freedom for Estonians followed. ${ }^{291}$ Due to the peasants' inability to consign themselves to a life of serfdom and increasing hardship, they began escaping the country. This left the landlords, dependent upon their labor, seeking a method to ensure their serfs would be forced to remain bonded to them and unable to flee. ${ }^{292}$ The feudal system was fully implemented, making the peasants little more than slaves. ${ }^{293}$

The heavy-handed rule of the Order of Teutonic Knights in the mid-1500s caused an international crisis, with Poland and Russia intervening and sending their armies ${ }^{294}$ In the upheaval, Northern Estonia pledged fidelity to Sweden's Erik XIV in $1561 .{ }^{295}$ After twentyfour years of war, Estonian lands were liberated of Russian military presence; Sweden maintained possession of Northern Estonia while Poland held Southern Estonia. ${ }^{296}$ The two regions were united under Sigismund III of Sweden and Poland and were later solely under Swedish rule in 1625 under Gustavus Adolphus II, who implemented reforms in Estonia aimed at improving the condition of the downtrodden peasantry ${ }^{297}$ For a few decades, the position of the Estonian peasantry varied as crown lands were privatized as awards to Swedish and Baltic-German nobility and then re-appropriated by the Swedish state under the Stockholm Diet of $1680 .{ }^{298}$ Crown lands observed work regulations and were therefore much more agreeable for the peasants forced to labor on them. ${ }^{299}$ Simultaneously, Sweden increased education opportunities for the peasantry. ${ }^{300}$ The "old good Swedish time" was a

\footnotetext{
${ }^{290}$ Ibid.

${ }^{291}$ Ibid.

292 Ibid.

293 Ibid.

${ }^{294}$ Ibid.

${ }^{295}$ Ibid.

${ }^{296}$ Ibid, 19.

${ }^{297}$ Ibid.

${ }^{298}$ Ibid.

${ }^{299}$ Ibid.

${ }^{300}$ Ibid.
} 
bright point in hundreds of years of foreign domination of Estonian lands. The "progressive economic and cultural development initiated during Swedish rule was discontinued by warring European powers. ${ }^{301}$

The Great Northern War (1700-1721) and signing of the Nystad treaty concluded progressive Swedish rule in Estonia and introduced crippling Imperial Russian domination, which in turn reinstated serfdom in the harshest sense. ${ }^{302}$ Even liberal Russian reforms were resisted by the Baltic-German nobility who were "interested in making these conditions [of serfdom] last as long as possible," and who had sought Russian intervention on Swedish rule for fear of losing their noble rights as the institution was gradually phased out. ${ }^{303}$

The Russian government was later forced to concede to reforms on serfdom in the mid-1800s and by 1861 the institution was formally abolished. ${ }^{304}$ Regulation of the sex industry coincided with the emancipation of the peasants and the introduction of industrialization. ${ }^{305}$ Women were given fewer economic opportunities; they were barred from ownership of land and were paid only a fraction of the wages men made. ${ }^{306}$ Working conditions were especially bad for Russian women, many of whom chose to supplement their meager incomes with prostitution - either off the books or as legally registered prostitutes. ${ }^{307}$ Many prostituting women came from the ranks of domestic service: various contemporary surveys reported numbers between forty and fifty percent. ${ }^{308}$ Women working

\footnotetext{
301 Ibid.

302 lbid, 20.

303 Ibid, 20-21.

${ }^{304}$ Bernstein, 4.

${ }^{305}$ Laura Englestein, "Gender and the Juridical Subject: Prostitution and Rape in Nineteenth-Century Russian Criminal Codes," The Journal of Modern History 60, 3 (Sep., 1988): 458-495, 485; Bernstein, 4.

${ }^{306}$ Bernstein, 4.

307 Ibid, 4.

308 Ibid, 107-108
} 
as domestic servants had difficult work with no "regular leisure time nor a standard hour to eat, drink, or sleep." 309

The establishment of a regulated sex industry in the same era as the dissolution of the institution of serfdom is significant. The status quo of a patriarchal social order was threatened by the emancipation of the peasants and the introduction of industrialization. ${ }^{310}$ The traditional Russian social hierarchy, which stipulated that a woman's behavior was regulated by her father, husband, or lord, began to dissolve. In addition to professedly protecting public health through the regulation of the sex industry, the state could also monitor and maintain control over women with no traditional patriarchal guardian. ${ }^{311}$

Prostitution was viewed as a "Western" phenomenon which had not existed in Russia until "Western industrialization" was imported. Prostitution became symbolic of "one of the malignant aspects of modern urban life," despite having existed prior to heightened Russian interaction with Europe or the adoption of industrialization. ${ }^{312}$ Marxist theory also identified prostitution as "endemic to capitalism." ${ }^{13}$ When put into context, it is understandable why the association was made. People began moving from the countryside to the cities, leaving farms for factory jobs. Often this urbanization of the population caused men with jobs in cities to lead double lives - one in the countryside with wives and families and another alone in the city. The situation of male workers living away from home - possibly seeing their families once a year - fueled the growth of the commercial sex industry. ${ }^{314}$ At the same time, there were ample numbers of women in the

\footnotetext{
${ }^{309}$ Ibid, 108-109.

310 Ibid, 6.

311 Ibid.; Engelstein, 462-464.

312 . Bernstein, 8.

313 Ibid, 121.

314 Ibid, 90.
} 
cities looking to supplement their incomes through prostitution. Furthermore, the sex industry is often concentrated in cities for the simple reason of higher possible profits.

The Russian Revolution and World War I were breaking points for the ties binding Estonia to Russia. Independent Estonia emerged on February $24^{\text {th }}, 1918$ after a determined fight for liberation. ${ }^{315}$ During the era of the First Estonian Republic, prostitution was legal and regulated. Major cities had the greatest number of registered prostitutes, which remained fairly stable during the interwar period. In Tallinn there were 387 registered prostitutes in $1920 .{ }^{316}$ The number increased to 455 in $1940 .{ }^{317}$ The relatively constant statistics speak to the optimism and financial improvement that came with this renewed period of independence. Approximately ninety percent of Tallinn prostitutes were Estonian, while $8 \%$ were Russian. ${ }^{318}$ The majority of prostitutes were between the ages of 20-25 (approximately fifty percent) but a significant number were under the age of 20 (approximately thirty percent). ${ }^{319}$

Though Estonia had gained independence with the First World War, the opposite was the outcome of the Second World War. Estonia was occupied and forcibly annexed as part of the Soviet Union on August $6^{\text {th }}, 1940$. The first Soviet occupation lasted until German domination in August 1941, during which time, "Soviet authorities proceeded with all possible speed to destroy the political, economic and cultural life of independent Estonia." ${ }^{220}$ This included nationalization of production means, deportations, arrests,

\footnotetext{
${ }^{315}$ Raud, 23.

${ }^{316}$ International Organization for Migration, "Trafficking in Women and Prostitution in the Baltic States: Social and Legal Aspects,"( January 1, 2001), 162.

${ }^{317}$ Ibid.

${ }^{318}$ Ibid.

${ }^{319} \mathrm{Ibid}, 162-163$.

${ }^{320}$ Raud, 31.
} 
executions, and cultural suppression. ${ }^{321}$ In this first wave of deportations, which commenced on the $14^{\text {th }}$ of June, 1941, approximately 10,000 Estonians were deported to Siberia. ${ }^{322}$ This included registered prostitutes who were considered socially undesirable. ${ }^{323}$

Following the period of German occupation, the Red Army re-annexed Estonia in $1944 .{ }^{324} \mathrm{~A}$ fresh wave of murders, deportations, and cruelty followed. In one deportation alone, three percent of the 1945 Estonian population were displaced or perished in the process. ${ }^{325}$ The standard of living for Estonians rapidly and dramatically declined under Soviet occupation. ${ }^{326}$

During Soviet occupation in the years 1941-1941 and 1944-1991, the laws of Estonia were changed to match Soviet ideology. This included prostitution, which was declared part of a "parasitic lifestyle" ${ }^{327}$ Socialist thinking made a link between the manipulation of wealth disparities and prostitution and believed that the sex industry would naturally be destroyed with the elimination of classes and exploitation. ${ }^{328}$ This was not the case in reality as prostitution continued in the Soviet Union. Regardless, in the mid-1930s the government declared that prostitution had been eradicated and had no possibility of return. ${ }^{329}$ There was no legal measure criminalizing prostitution because the government refused to acknowledge

\footnotetext{
321 Ibid.

${ }^{322}$ Rein Taagepera, "Soviet Collectivization of Estonian Agriculture: The Deportation Phase," Soviet Studies 32,3 (July, 1980): 379-397, 380-381; Mart Laar, “Deportation from Estonia in 1941 and 1949," Estonia Today, Estonian Ministry of Foreign Affairs (June 2006), 1.

${ }^{323}$ Saar, 163.

324 Laar, 2.

325 Laar, 2.

${ }^{326}$ Raud, 32.

327 Saar, 163.

${ }^{328}$ Elizabeth Waters," Restructuring the 'Woman Question': Perestroika and Prostitution," Feminist Review 33 (Autumn, 1989): 3-19, 2.

${ }^{329}$ Ibid.
} 
that it existed; in the government's mind, there was nothing to criminalize. ${ }^{330}$ This general inattention and silence about the sex industry was maintained until the mid-1980s and the introduction of glasnost and perestroika. ${ }^{331}$ There was a rise in occurrence of prostitution in the mid-1980s, along with increased interaction with foreigners, the initial signs of private business, and income discrepancies. ${ }^{332}$ In addition, the media was under less state censorship and it was possible to discuss the sex industry. ${ }^{333}$ Admission of the continued existence of a sex industry in the Soviet Union led to great consternation and finally a legal action making prostitution "an administrative offence" in $1987 .{ }^{334}$ The law would not last long, as the Soviet Union would be formally dissolved in 1991.

Estonian re-independence brought legal change yet again. The period from 19911995 brought an explosion of the sex industry and extreme liberalization of the attitudes toward openly discussing sex and public display of erotic materials. ${ }^{335}$ The sex industry went from underground to easily observable and the number of prostitution venues increased dramatically. Given the repression of the Soviet administration, this phenomenon was unsurprising and calmed by 1996 with "changes in legislation, formation of a more stable market, and changes in the public opinion". ${ }^{336}$ Prostitution venues also declined in number. Uncertain economic situations - such as that of Estonia in the early to mid-1990s contribute to an increase in the number of women working in the sex industry.

\footnotetext{
${ }^{330}$ Ibid, 4.

${ }^{331}$ Ibid, 2.

332 Tatyana Mamonova, “USSR: Perestroika, Pornography, and Prostitution," GenderWatch 2, 2 (Sept. 1991): 12; Saar, 163.

${ }^{333}$ Waters, 4.

${ }^{334}$ Ibid.

${ }^{335}$ Saar, 164.

${ }^{336} \mathrm{Ibid}$.
} 
Legislation to regulate prostitution was presented to Parliament in 1993, but failed to be implemented. ${ }^{337}$ It was determined that there was insufficient support for either criminalization or legalization (and regulation) of prostitution, and therefore no type of legislation could be passed. ${ }^{338}$ This gave prostitution the awkward legal situation of being neither legalized nor criminalized. Acting as a pimp or procurer has been criminalized, however.

The reluctance to criminalize the purchase or selling of sex is compatible with Estonia's economic approach of fiscal conservatism. The country has followed such an economic course from the establishment of re-independence, "including budgetary balance, a strict currency board-type monetary rule, a fixed exchange rate to the German mark and a functioning bankruptcy law." ${ }^{339}$ Economic reforms began as early as the introduction of the policies of glasnost and perestroika. ${ }^{340}$ Experiments on the light industry sector were followed by reforms in other industries, an update to the wage system, and the establishment of joint ventures and an Estonian foreign trade association (ESTIMPEX). ${ }^{341}$ There was a period of hardship, during which many people lost their jobs. Some attempted to find employment abroad. The Russian minority was especially impacted, making it unsurprising that the demographics of the sex industry changed and that human trafficking became a problem.

\footnotetext{
${ }^{337}$ Ibid, 166.

${ }^{338}$ Ibid.

339 R.A. Panagiotou , "Estonia's Success: Prescription or Legacy?" Communist and Post-Communist Studies 34 (2000): 261-277, 266

${ }^{340}$ Ibid, 271; John Hoag and Mark Kasoff, “Estonia in Transition,” Journal of Economic Issues 33, 4 (Dec. 1999): $919-$ 931, 920.

${ }^{341}$ Panagiotou, 271.
} 
Upon independence, the Estonian system was significantly more prepared to restructure the economy than the two other Baltic States. ${ }^{342}$ Estonia was the first of these to introduce a national currency (June 1992) as well as a tax system reform, liberalization and reorientation of foreign trade, liberalization of prices, and privatization. ${ }^{343}$ When the time came that these economic changes had to be made after the Soviet economy's collapse, Estonians already had some experience with market reforms and were therefore significantly more comfortable with the change and discomfort brought by shock therapy. ${ }^{344}$ The result was one of the best growth rates in Europe during the late 1990s and early 2000 s. $^{345}$

The global economic crisis hit Estonia with particular intensity; the Estonian GDP fell 3.7 percent in 2008 and then 14.3 percent in 2009 while unemployment dramatically increased. ${ }^{346}$ The average gross monthly wage fell ten percent between the third quarter of 2008 to the second quarter of $2009 .{ }^{347}$ The financial problems in Estonia following the global economic crisis are relevant to a discussion of human trafficking in that country, especially as they pertain to certain demographics which form a major contribution to the feasibly available supply of persons for trafficking. According to statistics from the International Organization of Migration and used by Marion Pajumets, an estimated 500 people per year are trafficked from a point of origin in Estonia. ${ }^{348}$ Post-global economic recession Estonia

\footnotetext{
${ }^{342}$ Panagiotou, 272.

${ }^{343}$ Parts, 270; Hoag, 922-923; Panagiotou, 272.

${ }^{344}$ Hoag and Kassoff, 919.

345 Parts, 270.

${ }^{346}$ Parts, 269-270.

347 Ibid.

${ }^{348}$ Marion Pajumets, "Prostitutsioon - kas ühiskondlik probleem? Arvamused nähtuse olemusest, põhjustest, tagajärgedest [Prostitution - a social problem? Views on its nature, causes and effects]," Translated by Ilvi JõeCannon., Tallinn: Eesti Naisuurimus- ja Teabekeskus, EV Sotsiaalministeeriumi võrdõiguslikkuse osakond, Põhjamaade Min (2004), 20.
} 
was hindered by an increased cost of living combined with a decrease in average real income and living standards. ${ }^{349}$

The high unemployment rate during the global recession pushed workers unable to find jobs within the country to seek employment elsewhere. This was an especially noticeable trend among young, educated people. The unemployment rate of persons aged 15-24 rose to 29.2 percent in the third quarter of 2009 , an increase of 14.7 percent from $2008{ }^{350}$ For example, doctors trained in Estonian universities are often more attracted to jobs offered abroad after completion of their medical training, as they will earn considerably more in other countries, such as neighboring Finland. This normalized the movement of Estonian nationals to other countries for the purpose of work.

Ease of transit is an important factor in the international transfer of victims. Estonians are among the most commonly found foreign women in the sex trades of both Sweden and Finland. ${ }^{351}$ While travel between all Schengen Agreement countries is easy, movement between these countries is exceptionally easy, with multiple ferries and flights daily. ${ }^{352}$ This travel stimulates the bus, ferry, and hotel industries, allowing others along the route to profit from the trafficking of human beings. ${ }^{353}$ The fact that twenty-six percent of women involved in prostitution in Estonia have also been active in the Finnish sex industry is an illustrative point as to the fluid nature of movement in the region. ${ }^{354} \mathrm{~A}$ further eight

\footnotetext{
${ }^{349}$ Maris Kask and Anna Markina, "Trafficking for Forced Labour and Labour Exploitation in Estonia," in Trafficking for Forced Labour and Labour Exploitation in Finland, Poland and Estonia, edited by Anniina Jokinen, Natalia Ollus and Kauko Aromaa (Helsinki: Prevention of and Fight against Crime, 2011), 246-308; 250.

350 Ibid.

${ }^{351}$ Cecilia Englund, et al, "The Organisation of Human Trafficking: A Study of Criminal Involvement in Sexual Exploitation in Sweden, Finland and Estonia," Swedish National Council for Crime Prevention (Brottsförebyggande rådet - Brå), Stockholm (2008); 7.

${ }^{352}$ Swedish National Police Board, 10; Wennerholm, 13.

${ }^{353}$ Wennerholm, 13.

${ }^{354}$ Pettai, Kase, and Proos, 24.
} 
percent have worked in Germany, seven percent in Sweden, seven percent in Norway, six percent in The Netherlands, six percent in Russia, five percent in the United Kingdom, and five percent in Latvia. ${ }^{355}$

According to the statistics collected by the NGO Living for Tomorrow, which maintains a hotline for possible human trafficking victims as well as consultation services for potential international workers, the profile of an individual considering pursuing work abroad is not cohesive, though there are some patterns. The education level of hotline callers varied. The majority, at 47 percent, had obtained vocational training, while 32 percent had secondary education and 20 percent had higher education. ${ }^{356}$ One percent had acquired only primary school education. ${ }^{357}$ Though the ages of callers also varied, there were no underage callers represented. A narrow plurality of $18 \%$ was in the age range of $22-$ $26{ }^{358}$ When added to the number of $18-21$ year olds, the total number of young adults comprised 33 percent of callers. ${ }^{359}$ This corresponds with the theory that the young are highly affected. It also correlates with the education level of the victims, supporting the idea that young and educated people, who have fewer opportunities for employment in Estonia, are an at-risk group. The other age groups and their percentage representations among callers include nine percent between the ages of 27 and 30, twelve percent between 31 and 35, nine percent between 36 and 40, fifteen percent between 41 and 45, thirteen percent between 46 and 50, and eleven percent age 50 and above. ${ }^{360}$

\footnotetext{
${ }^{355}$ Ibid.

${ }^{356}$ NGO Living for Tomorrow, "Human Trafficking prevention and victim assistance Hotline statistics 2011." NGO Living for Tomorrow, 2012, 8.

${ }^{357}$ Ibid.

${ }^{358}$ Ibid, 7.

${ }^{359}$ Ibid.

${ }^{360}$ Ibid.
} 
The gender ratio of calls in 2011 indicated a slightly higher representation of women to men, at 55 percent women versus 45 percent men ${ }^{361}$ In 2012, more men were represented at 59 percent men versus 41 percent women. ${ }^{362}$ This might be surprising to those who estimate the number of trafficking victims based upon the media or even some government and NGO focus. Often the discourse - and policy - has been focused solely on human trafficking for the purpose of sexual exploitation, rather than on human trafficking as an cohesive phenomenon encompassing all types. Most notable in Estonia at the moment is labor exploitation, which in 2011 comprised a total of 20 cases - a vast majority at 86 percent of the cases the NGO Living for Tomorrow was involved with. ${ }^{363}$ Labor exploitation, according to the numbers, affects men more frequently than women at a ratio of 4 women to 16 men. ${ }^{364}$ Sexual exploitation and fictitious marriages were represented fully by women. ${ }^{365}$

In Estonia there is an observed ethnic element to human trafficking cases. According to Living for Tomorrow statistics, 80 percent of calls were from Russian-speakers. ${ }^{366}$ The majority of calls (70.75 percent) originated in Tallinn, where the NGO is based ${ }^{367}$ Most calls came from citizens of Estonia (78 percent), though aliens were represented at 12 percent and foreigners with legal permission were represented at 8 percent. ${ }^{368}$ Identity politics remain strong in the country, with the population divided between ethnic Russians

\footnotetext{
${ }^{361}$ Ibid, 6.

${ }^{362}$ NGO Living for Tomorrow, "Human Trafficking prevention and victim assistance Hotline statistics 2012," NGO Living for Tomorrow, 2013.

${ }^{363}$ NGO Living for Tomorrow 2012, 16.

364 Ibid.

365 Ibid.

${ }^{366}$ NGO Living for Tomorrow 2012, 12.

${ }^{367}$ Ibid, 9.

368 Ibid, 11.
} 
and ethnic Estonians. ${ }^{369}$ The scope of this thesis cannot include a full investigation into the social issues regarding the Russian-speaking minority. It is, however, clear that a disproportionate number of this demographic are affected by trafficking in the Baltic countries due in part to the marketability of monoglot ethnic Russians unable to compete in job markets in which either the official state language or multiple languages are required..$^{370}$ This makes it unsurprising that the majority of prostitutes are now Russian. As of 2006, 59 percent of respondents to Pettai, Kase, and Proos' survey were Russian, while 31 percent were Estonian. ${ }^{371}$ Additionally, a large number of these Russian prostitutes were stateless approximately one-third. ${ }^{372}$ It is also notable that Russian-language media outlets feature human trafficking more prominently than Estonian-language media outlets do.

Another significant component of human trafficking suppression is the threat of punitive penalty to a trafficker. Strong laws with successful prosecution are strong deterrents to trafficking. Until 2012, there was not an adequate law in Estonia addressing all forms of human trafficking. The main concern has been regarding labor exploitation, which was not prosecuted as human trafficking. Most cases of labor exploitation were previously treated as cases of fraud or as cases "related to human trafficking." prosecute trafficking cases, focusing on individual factors, such as enslavement, abduction, and fraud.

Denial of the existence of a human trafficking problem led to Estonia's "blacklisting" on the U.S. State Department's annual Trafficking in Persons (TIP) Report in 2011.

\footnotetext{
369 Jelena Helemäe and Ellu Saar, "Estonia - Highly Unequal but Classless?," Studies of Transition States and Societies 4, 2 (November 2012): 49-58; 49-50.

${ }^{370}$ Englund, et al, 8; Wennerholm, 13.

${ }^{371}$ Pettai, Kase, and Proos, 7.

372 Ibid.

${ }^{373}$ Kask and Markina, 261.
} 
Previously a Tier-2 country, Estonia was placed on the Tier-2 Watch List. Tier-2 countries are those "whose governments do not fully comply with the TVPA's minimum standards, but are making significant efforts to bring themselves into compliance with those standards." ${ }^{374}$ Tier-2 Watch List countries have the same basic definition, with the additions that:

a) The absolute number of victims of severe forms of trafficking is very significant or is significantly increasing;

b) There is a failure to provide evidence of increasing efforts to combat severe forms of trafficking in persons from the previous year; or

c) The determination that a country is making significant efforts to bring itself into compliance with minimum standards was based on commitments by the country to take additional future steps over the next year. ${ }^{375}$

The Tier-2 rating was regained after improvements in the law.

Article 133 of the Estonian penal code, as of the changes in 2012, is the main provision addressing human trafficking as a crime and includes forced prostitution, begging, criminal activity, and with unusual conditions. Penalties range from a sentence of imprisonment for one to seven years. The article is as follows:

(1) Placing a person in a situation where he or she is forced to work under unusual conditions, engage in prostitution, beg, commit a criminal offence or perform other disagreeable duties, or keeping a person in such situation, if such act is performed through deprivation of liberty, violence, deceit, threatening to cause damage, by taking advantage of dependence on another person, helpless or vulnerable situation of the person, is punishable by 1 to 7 years' imprisonment.

(2) The same act, if:

\footnotetext{
374 Office to Monitor and Combat Trafficking in Persons, "Tier Placements: Trafficking in Persons Report 2011," United States Department of State (2011).

${ }^{375}$ Ibid.
} 
1) committed against two or more persons;

2) committed against a person of less than 18 years of age;

3) committed against a person in a helpless situation;

4) committed in a torturous or cruel manner;

5) serious health damage is caused thereby;

6) danger to life is caused thereby;

7) committed by two or more persons;

8) committed by taking advantage of official position,

9) serious consequences are caused thereby; is punishable by 3 to 15 years' imprisonment.

(3) An act provided for in subsection (1) or (2) of this section, if committed by a legal person, is punishable by a pecuniary punishment or compulsory dissolution.

(4) For criminal offence provided in this section, the court shall impose extended confiscation of assets or property acquired by the criminal offence pursuant to the provisions of $\S 832$ of this Code.

(5) For the purposes of this section, vulnerable situation is a situation where a person lacks an actual or acceptable opportunity not to commit any of the acts specified in subsection (1) of this section.

For the reporting period covered by the State Department's 2012 TIP Report, "Estonian authorities conducted three new investigations and prosecuted one trafficking offender under the existing Article 133,"with no resulting convictions. ${ }^{376}$

In addition to targeting the actual act of trafficking, Article 133(1), prosecutes support to human trafficking operations, including "transportation, delivery, escorting, acceptance, concealment or accommodation," through force with a penalty of up to five years imprisonment. Aggravating factors, such as the crime being committed against two or more persons or against a minor incur a penalty of two to ten years imprisonment. Also

${ }^{376}$ United States Department of State, "Trafficking in Persons Report: Countries D-I," 2012, 153. 
included in Article 133 are provisions against pimping and "aiding prostitution." The human trafficking for the forcible removal of tissues or organs is addressed in Articles 138, 139 , and 140.

Due to the very recent inclusion of the 2012 provision, which recognizes human trafficking as a criminal act in itself, it has been highlighted that an accurate assessment of efficacy is currently impossible to make with any depth. ${ }^{377}$ It is already clear, however, that there is room for improvement in several areas. ${ }^{378}$ More resources - both human and monetary - should be devoted to the issues of labor exploitation and forced labor. ${ }^{379}$ This is important during this "development phase" of cooperation between NGOs and Estonian governmental institutions, as they introduce the Deployment Plan for Reducing Violence for the period of 2010-2014, of which human trafficking is one of four targeted areas. ${ }^{380}$ A criticism of the current legislation which has already been identified targets the confusing roles of different agencies, which have a need for increased clarification, communication, and cooperation. ${ }^{381}$ This would increase the efficacy of anti-human trafficking initiatives by ensuring that multiple methods are in use simultaneously and streamlining the system so that the same strategy is not being used by multiple projects.

There has been confusion over implementation of the legislation and identification of victims from the legal perspective. NGOs are having difficulties in referring some cases to

\footnotetext{
${ }^{377}$ Stella Rössborn, “Estonia: Report on Cooperation between Stakeholders at the National Level in Estonia to Address Trafficking for Labour Exploitation," Peace and Security Consulting for Task Force against Trafficking in Human Beings of the Council of the Baltic Sea States, 2012, 8.

${ }^{378}$ Ibid; United States Department of State, "Trafficking in Persons Report: Countries D-I," 2012, 153.

${ }^{379}$ Ibid.

${ }^{380}$ Stella Rössborn, Bjarney Friđriksdóttir, Anna Ekstedt, Anthony Jay, and Vineta Polatside, "Actors against Trafficking for Labour Exploitation: Report on Cooperation Between Stakeholders at the National Level in the countries of the Baltic Sea region to Address Trafficking for Labour Exploitation," The Council of the Baltic Sea States, 2013, 24-25; Rössborn 2012, page 8.

${ }^{381}$ Ibid, page 8.
} 
assistance because "they are not legally recognized as victims of a crime" by the current definition. ${ }^{382}$ For example, in cases of labor exploitation, the current provision simply may not be precise enough. It includes forcing a person into a disagreeable working situation, but proof may be hard to verify conclusively. Perhaps the force was verbal or implied. A disagreeable working situation is not defined, but rather left to interpretation. A more encompassing and full definition is necessary in order to successfully prosecute cases. It is often difficult to determine victimhood status due to the lack of a clear definition in the new law, making possible human trafficking cases being prosecuted under anti-fraud legislation an ongoing problem. According to the U.S. State Department, "Prosecutors allegedly lack experience trying trafficking cases and have difficulty constructing trafficking cases because of victims' unwillingness to testify given uncertainties in the victim protection scheme." ${ }^{383}$ Additionally, cases are often tried in administrative court as opposed to criminal court, which is costly for the victims, who, having been exploited, are unable to pay for court costs. ${ }^{384}$ The deterrence power of the legal system is only effective if there are successful prosecutions. Additionally, the lack of prosecuted cases is problematic due to a governmental perception that a low number of prosecutions indicate human trafficking does not exist in Estonia and therefore does not need to be addressed through combative policies. ${ }^{385}$

There is a flourishing sex industry in Estonia, where prostitution is legally ambiguous. If "the state does not interfere in the activities of adult prostitutes" or the selling of sex, it outlaws enticing someone into prostitution, pimping or procuring prostitutes,

\footnotetext{
382 Ibid.

${ }^{383}$ US Department of State 2012, 2.

${ }^{384}$ Rössborn, et al. 2013, 25.

${ }^{385}$ Kelly Hyland Heinrich, "Ten Years After the Palermo Protocol: Where are Protections for Human Trafficking Victims?," Human Rights Brief, 2010. Rössborn 2012, 8.
} 
prostitution advertisement, and the rental of apartments for prostitution. ${ }^{386}$ The Estonian government is not an active participant in "projects carried out in Estonia to map out prostitution, to help prostitutes and to prevent sex business." ${ }^{387}$ It is estimated that there are 2,000 - 3,000 prostitutes in Estonia. ${ }^{388}$ Though there "is a rather widespread belief in Estonia that prostitution is a voluntary choice," many respondents to a survey of Estonian prostitutes either "refused to admit their ties to the sex trade," or defined involvement in the sex trade as "relations with sponsors" ${ }^{389}$ This indicates that there is a high level of stigma and shame for prostitutes in Estonia, which would not be the case if participation in the industry were completely voluntary. It is likely that the sex industry has not been addressed by Estonia for two reasons. ${ }^{390}$ First, the Estonian economy is highly free-market; banning an economic sector due to moral values would not be in line with the neoliberal economic reasoning that has guided the country since its post-Soviet reforms. Second, the Estonian government does not have a previous history of devoting much time and money to social issues. This is changing to a certain extent at the present. Previously, the government was focused on restructuring the economy after regaining independence from the Soviet Union, with the hope that a strong economy would itself be a solution to social issues.

There is also the more hidden matter of the patriarchal nature of Estonian society, especially when compared to Sweden. For example in politics, of 101 parliament seats, 20 are held by women and of 13 cabinet positions, only one is held by a woman. ${ }^{391}$ Gender equality has not been actualized; Estonian society is generally unaware of the extent of

\footnotetext{
${ }^{386}$ Pajumets, 57-58.

387 Ibid, 20.

${ }^{388}$ Pettai, Kase and Proos, 9.

389 Ibid, 13, 16-17.

${ }^{390}$ Prostitution was regulated during the First Republic.

${ }^{391}$ United States Department of State, "Country Reports on Human Rights Practices for 2012: Estonia," Bureau of Democracy, Human Rights and Labor, 2013.
} 
gender inequality in the country. Because they are unaware, Estonians are less critical of the current gender inequalities than their Finnish neighbors, who perceive more inequality because they are better informed through public discourse. ${ }^{392}$ This is a problem, as "the fact that inequality of women and men is hidden and unacknowledged only perpetuates this situation, because people see no need or reason to interfere." ${ }^{393}$ For example, in both Finland and Estonia, 85 percent of healthcare workers and 90 percent of social workers are women. ${ }^{394}$ The difference is that Finns are more supportive of increasing the number of men in these fields while also increasing the number of women in traditionally male-dominated jobs than Estonians are. ${ }^{395}$ There is also a high level of female financial dependence in Estonia, with approximately half of women reliant on their male partner, a phenomenon which usually occurs after having children and leaving the workforce to take care of them. ${ }^{396}$ Explanations for entering the sex industry vary and often involve a set of personal factors. Hedin and Månsson have found that that troubled relationships with parents were a consistent theme in the lives of the prostituted women they interviewed. ${ }^{397}$ The number of Estonian women involved in prostitution who were raised in "normal" circumstances by both parents is relatively low, at half, while a quarter were raised by either single parents or grandparents. ${ }^{398}$ Ten percent were raised by foster parents. In addition, eight percent were

\footnotetext{
392 Liina Järviste, “Gender Equality and Inequality: Attitudes and Situation in Estonia in 2009," Ministry of Social Affairs, 3/2010.

${ }^{393} \mathrm{Ibid}, 26$.

${ }^{394}$ Ibid, 7.

${ }^{395}$ Ibid.

${ }^{396}$ Ibid, 26.

${ }^{397}$ Hedin and Månsson, 227.

${ }^{398}$ Pettai, Kase and Proos, 9.
} 
raised in orphanages. ${ }^{399}$ These statistics display a strong link between family breakdown and increased likelihood to enter prostitution.

A history of childhood abuse was reported in varying degrees, from solitary occasions to constant mistreatment. ${ }^{400}$ The most common perpetrators of childhood abuse were "fathers, brothers, and other relatives," but there is noted "bitterness toward...mothers, who failed to discover the abuses and who could not or did not try to protect their daughters. ${ }^{401}$ A quarter of the women interviewed in Hedin and Månsson's study, however, said they had grown up with adequate attention from supportive parents. ${ }^{402}$ Of Estonian prostitutes surveyed and reporting having been raped, one third of respondents reported being raped between the ages of 12 and $14{ }^{403}$ By age 16 , the statistic increased to include two-thirds of all respondents reporting at least one incident of rape. ${ }^{404}$

Once involved in the sex industry, "the women encountered destructive relationships in which they were exposed to violence, threats and degradation that mirrored childhood trauma." ${ }^{405}$ A failure to be taught by families how to bond with others and form close relationships puts many women at a disadvantage, creating an opening for pimps to exploit them. ${ }^{406}$ Relationships are one key factor in entrance to the sex industry. If a person has close friends or relatives involved in the sex industry, it is more likely that this person will also adopt prostitution as "a very reasonable, logical and viable option," particularly if their

\footnotetext{
${ }^{399}$ Ibid.

${ }^{400}$ Hedin and Månsson, 226-227.

${ }^{401}$ Ibid.

402 Ibid, 227.

${ }^{403}$ The idea of what constitutes rape may have been understood differently by those surveyed. Pettai, Kase and Proos (page 12) also reported that many women (24\%) could not or refused to define rape or experienced incidences.

Pettai, Kase and Proos, 12.

${ }^{404}$ Ibid.

${ }^{405} \mathrm{Ibid}, 232-233$.

${ }^{406} \mathrm{Ibid}, 228$.
} 
circumstances become "further compounded by a multitude of external pressures, of a financial, domestic and personal nature." ${ }^{407}$ It is possible that a close proximity to the sex industry normalizes the concept of sex-selling. Relationships outside of the sex industry are "gradually lost." ${ }^{408}$ This loss of a social network outside the industry isolates prostituted women and makes them more dependent and therefore easier to exploit continuously.

Pettai, Kase, and Proos' survey indicates that there is a clear age factor in the Estonian prostitution industry. A mere six percent of the responding prostitutes were over the age of 35 , with most (56 percent) being in the 18 to 25 demographic. ${ }^{409}$ Education was generally low, with 66 percent completing only primary or basic education. ${ }^{410}$ A quarter of the respondents to the survey had completed secondary education. ${ }^{411}$

In Pettai, Kase and Proos' study, Estonian prostitutes were interviewed about their participation in the sex industry. This included recounting previous life experiences, the conditions of their work as prostitutes, and their possible exit from the industry. Violence was pervasive, with the majority responding that the most important quality a prostitute could have was an "ability to handle difficult (abusive) clients." ${ }^{\prime 12}$ The study's results indicated that the Estonian sex industry is not a positive "work environment". Concerning rates of abuse, 59 percent reported psychological abuse and 29 percent reported physical violence from customers. ${ }^{413}$ Mediators (i.e., pimps) reportedly engaged in psychological abuse against 31 percent of respondents while 13 percent of respondents reported physical

\footnotetext{
${ }^{407} \mathrm{Min}, 329-330$.

${ }^{408}$ Ibid, 230.

${ }^{409}$ Pettai, Kase and Proos, 38.

${ }^{410}$ Ibid, 9.

${ }^{411}$ Ibid.

412 Pettai, Kase and Proos, 15.

${ }^{413}$ Ibid, 26.
} 
violence perpetrated by mediators. ${ }^{414}$ The same women were afraid or unable to respond fully to some questions, such as those regarding experiences of rape; 19 percent responded that they had been raped by customers, while 9 percent had been raped by mediators. ${ }^{415}$ It is possible that the definition of abuse and violence differ in respondents' minds compared to the definition that would be provided by an individual with no involvement in the sex industry. ${ }^{416}$ This is supported by the findings of the study, as 47 percent admitted suffering "minor bodily harm" from customers, while only 29 percent consider themselves sufferers of physical abuse. ${ }^{417}$ Health problems were common and varied, including psychological stress disorders (45 percent), digestive ailments (42 percent), problems afflicting extremities (34 percent), back or neck problems (30 percent), skin diseases and allergies ( 25 percent), respiratory or pulmonary ailments (22 percent), venereal diseases (21 percent), poor eyesight (14 percent), and circulatory system troubles (14 percent). ${ }^{418}$ Gynecological issues were also prevalent. Half the respondents had abortions, 35 percent suffered from gynecological diseases, and a quarter suffered from venereal diseases. ${ }^{419}$

The same study also focused on those women who were considering leaving or had already left the industry in an attempt to assess what assistance and support would be most desired and the reasons for remaining in prostitution. A large percentage, 59 percent, felt that they required "help and support." ${ }^{420}$ Those who responded positively to having attempted to break from the industry indicated various reasons for their failure to enter the regular workforce. The most common one was the inability to find another profitable job

\footnotetext{
${ }^{414}$ Ibid.

${ }^{415}$ Ibid.

${ }^{416}$ Ibid, 12.

${ }^{417} \mathrm{Ibid}, 27$.

${ }^{418}$ Pettai, Kase and Proos, 28.

${ }^{419}$ Ibid.

${ }^{420}$ Pettai, Kase and Proos, 35.
} 
(48 percent), followed by pressure from being the main earner of the household (33 percent), being in debt (31 percent), dissatisfaction with previous legitimate jobs (21 percent), and someone forcing or coercing them to remain in the sex industry (16 percent) ${ }^{421}$ The survey indicated those needs which prostitutes desirous of exiting the industry found to be most important. These included "help in finding legal work, financial support, medical aid, support for learning legitimate profession, [and] shelter..." ${ }^{422}$ Assistance services which were considered important but not vital included free medications or contraceptives, psychological support, and a supportive person on whom to lean. ${ }^{423}$ The responding women understood that the reasons they were forced to remain in circumstances of prostitution were largely economic. Other concerns were caused by the prostitution itself or by previous problems in the women's lives. Pettai, Kase and Proos concluded that the "best motivator for women to leave the sex industry is money," as 92 percent of respondents "chose this option as the biggest motivator." ${ }^{424}$

Sallmann's study of prostituted women identified a trend among those who had discontinued prostitution (and substance abuse in this case) and who, "still defined themselves by their prior activities." ${ }^{425}$ The long-term damage is evident in one interview in particular:

B. T.: The damage is done.

Interviewer: And what do you think the damage is?

\footnotetext{
${ }^{421}$ Ibid, 34.

${ }^{422}$ Ibid, 36.

${ }^{423}$ Ibid.

${ }^{424}$ Ibid, 37.

${ }^{425}$ Sallmann, 153.
} 
B. T.: My spirit, my health. Um, my mind, because it's never going to leave me. I'm, you know, even when I'm not selling my body, I was still a prostitute. Before in the past, you know." 426

Substance abuse among prostitutes is common. In order to escape their reality, a variety of narcotics and alcohol are used. In Sallmann's study, "All the participants self-identified as struggling with a substance use problem throughout most or all of their involvement in prostitution." ${ }^{427}$ This is corroborated by Hedin and Månsson, who found, "The women coped with the trauma of sexual abuse and subsequent symptoms of PTSD via drug and alcohol use." ${ }^{228}$

Pettai, Kase and Proos' study found that half of the women surveyed had used painkillers within the past month while 29 percent had used tranquilizers, a sharp contrast with the total number of women in Estonia using them, at 3 percent. ${ }^{429}$ The results indicated that 65 percent of Estonian prostitutes admitted abuse of narcotics while 35 percent claimed to have never used them. ${ }^{430}$ Of narcotic-abusing prostitutes tested, 82 percent were HIVpositive. ${ }^{431}$ These statistics indicate an HIV problem among prostitutes in Estonia, who are generally plagued by health problems. Of those who had been tested for HIV, 20 percent were HIV-positive. ${ }^{432}$ Unfortunately, half of the respondents to the survey had never taken an HIV test. ${ }^{433}$ Alcohol abuse was the most prevalent, with 88 percent under the influence of alcohol and 43 percent under the influence of narcotics while servicing clients. ${ }^{434}$ Alcohol abuse often begins at a young age, with the majority beginning consumption between the

\footnotetext{
${ }^{426}$ Ibid.

${ }^{427}$ Ibid, 150.

${ }^{428}$ Hedin and Månsson, 226-227.

${ }^{429}$ Pettai, Kase and Proos, 29.

${ }^{430} \mathrm{Ibid}, 31$.

${ }^{431} \mathrm{Ibid}, 30$.

${ }^{432}$ Ibid.

${ }^{433}$ Ibid.

${ }^{434}$ Ibid, 33.
} 
age of 15 and 16 (34 percent). ${ }^{435} \mathrm{~A}$ further 29 percent began drinking between the ages of 13 and 14, while another 24 percent began between the ages of 17 and $18 .^{436}$

The frequency of alcohol and narcotics use by Estonian prostitutes illuminate the fact that prostitutes are looking for a way to numb themselves from their realities and handle the situation. Mental health problems were common. Tension and stress were reported by 88 percent of respondents, followed by nervousness or anxiety at 72 percent, sleeplessness at 66 percent, depression at 64 percent, hopelessness at 53 percent, suicidal thoughts at 47 percent, and deliberate self-injury at 24 percent. ${ }^{437}$ It is difficult to imagine that an individual would freely choose to work or remain working in an industry that causes nearly half of workers to admit imagining suicide.

Concerning recruitment of women from Estonia involved in international trafficking cases, many went through a local mediator, or pimp, with international contacts, though 39 percent traveled independently and later found a mediator. ${ }^{438}$ Twenty percent of the women's recruitments were arranged by their boyfriends and labor recruitment firms were responsible for the recruitment of seventeen percent. ${ }^{439}$ According to the authors of the survey, this is indicative of Estonian mediators of prostitution being part of a larger, international network. ${ }^{440}$ Two-thirds of the women failed to establish a labor contract before leaving the country. ${ }^{441}$ Upon arrival to the destination country, ten percent learned that they were to work in the sex industry despite expecting another type of work. ${ }^{442}$ Sixty percent of

\footnotetext{
${ }^{435}$ Ibid, 31.

${ }^{436}$ Ibid.

${ }^{437}$ Ibid, 27.

${ }^{438}$ Ibid, 24.

${ }^{439}$ Ibid.

${ }^{440}$ Ibid, 25.

${ }^{441}$ Ibid.

${ }^{442}$ Pettai, Kae and Proos, 25.
} 
the women worked in countries where visas were not required, supporting the theory that open borders increases the ease of human trafficking. ${ }^{443}$ The majority that did obtain visas obtained tourist visas, while others were issued work visas. Therefore, even when visas were acquired, they were not legitimate in intent. Some women, 17 percent, were illegal with no visa at all. ${ }^{444}$

Human trafficking exists in Estonia, as elsewhere, in various forms. The decision by Estonian lawmakers to update the laws concerning human trafficking in 2012 was an important step in fully addressing the phenomenon as a whole. It is evident from increased government participation that the view of human trafficking as a problem to be addressed is developing. There are several areas for improvement in Estonia's approach to combatting human trafficking in all its forms. First, there must be a clear and strong body of legislation targeting varieties of human trafficking. The current provisions require further definition and rigorous application to make them effective. ${ }^{445}$ Prosecution under these laws is described as being difficult for victims, prosecutors, and judges who may not have a full understanding of the laws or their possible application. The definitions used at the state level must completely coincide with those used internationally to facilitate transnational cooperation on investigations, data collection, and successful prosecutions. ${ }^{446}$

Second, the sex trade must be addressed. Estonia would do well to follow in the footsteps of Sweden and target the purchase of sex. Such a move would be in line with the government's professed commitment to gender equality and would reduce human trafficking for the purposes of sexual exploitation. This focus on the sex industry would also

\footnotetext{
${ }^{443} \mathrm{Ibid}$. It is possible that the Schengen Agreement, therefore, makes human trafficking easier. ${ }^{444}$ Ibid.

445 United States Department of State, "Trafficking in Persons Report: Estonia," 2012, 1.

${ }^{446}$ Aromaa, 16.
} 
require a deeper conversation with an engaged society about sexual health, sex life, and gender roles in order to be effective and progressive. Because Estonia has a different set of cultural values and a different history than Sweden, it has not implemented the same type of legislation. The government of Estonia prefers neoliberal economic policies and has the tendency to remain distanced from any sort of strong, state-sponsored social action.

Meanwhile, Sweden has taken more progressive attitudes toward social issues and attempts to solve social problems through governmental intervention.

Finally, as Estonia is primarily a source country for victims of human trafficking, efforts should be applied in such a manner as to make prevention a key goal. There are many factors to consider in developing means of prevention, such as economic and social systems, as well as methods of prevention that can be applied immediately. These include outreach and education programs targeting potentially vulnerable populations. The engagement of Estonian civil society is extremely important to the improvement of social policy, such as that dealing with prostitution and human trafficking. Such an engaged civil society can both push for action by the government and act of its own accord to make the changes that are necessary. At the moment, there is an increase in the discussion of these topics.

This is evidenced by an increase in discussion on possible criminalization or regulation of the sex industry and its relationship with human trafficking. A number of opinion articles have been published in the media concerning prostitution in 2013. For example, after economist Andres Arrak wrote an opinion piece for Postimees advocating the legalization of prostitution, Katri Eespere of the Social Ministry expressed the opposite 
opinion the next week via the same newspaper. ${ }^{447}$ Eespere deftly highlighted the inaccuracies in Arrak's argument for legalized prostitution, which "may seem like a brilliant idea for any economist," but simply do not work. ${ }^{448}$ There have also been small but significant actions taken by the government, such as a sting operation on Tallinn cab drivers which began in February 2013. ${ }^{449}$ The operation only focused on one prostitution ring from a single company (Tulika) and detained a small number of drivers compared to the number involved in the sex industry. ${ }^{450}$ However, it was some action, indicating at least a minimal increase the Estonian government's interest level regarding the sex industry and furthermore, the action on the taxi drivers stimulated increased public debate and awareness. As these changes are ongoing at the present time, they must be supported and encouraged through effective cooperation between governmental and non-governmental organizations.

\footnotetext{
${ }^{447}$ Andres Arrak, "Prostitutsioon Tuleks Legaliseerida," Postimees, 12.07.2013; Katri Eespere, "Prostitutsiooni Legaliseerimine on Mõttetu," Postimees, 16.07.2013.

${ }^{448}$ Eespere 2013. It should be noted that there was even a flaw in the very basic argument that prostitution is able to be legalized, as it is not criminalized in Estonia, a point Eespere makes. It must therefore be assumed, then, that Arrak meant to endorse either the repeal of laws against organized prostitution and pimping, or was calling for regulation of the sex industry.

449 Loonet, 2013.

${ }^{450}$ Ibid.
} 


\section{FINDINGS AND CONCLUSIONS}

There is mounting evidence of the augmenting effects of legalized or regulated sex industries on human trafficking for the purpose of sexual exploitation. In Sweden, it has become much more complicated and expensive to operate such networks, reducing the profit for traffickers and requiring much more effort and risk. ${ }^{451}$ Even should such an undertaking be attempted, it is difficult to attract enough sex buyers to consistently support the business. ${ }^{452}$ Indoor prostitution is the only option, as street-based prostitution involves far greater risk of apprehension. ${ }^{453}$ As additional proof of the efficacy of the law, traffickers have been recorded discussing Sweden as an unappealing market. ${ }^{454}$ Testimony from recovered victims also supports this claim. ${ }^{455}$ This demonstrates efficacy.

Prostitution legalization does not aid in the reduction of human trafficking for the purpose of sexual exploitation, as has been lately observed in the Netherlands by Marinova and James in their study as well as various media outlets in the past year. ${ }^{456}$ In 2012 , the Office of the Dutch Rapporteur published a report for the years 2007-2011, noting that the number of reported cases of sexual exploitation in the Netherlands dramatically rose between 2009 and $2010 .{ }^{457}$ There is a growing body of evidence that the legal commercial

\footnotetext{
451 Ibid, 1200, 1209; Wahlberg, 5.

452 Wahlberg, 5.

453 Ekberg, 1201. Private apartments must be rented to house the prostitutes. In order to conceal the operation, the women must be moved frequently, making the cost of renting properties quite high.

${ }^{454}$ Wahlberg, 5.

455 Wahlberg, 5.

456 "Research on the Netherlands and Germany finds that legalization of prostitution does lead to an increase in trafficking;" Marinova and James, 247.

"A decade ago, the government in the Netherlands legalised prostitution in an effort to cut human trafficking and organised crime...But it seems their efforts have had the opposite effect. Amsterdam's mayor says the red light district has turned into a hub for human traffickers exploiting the country's liberal approach to selling sex"; Anne Holligan, "Can Amsterdam clean up the red light district?," BBC, July 5th, 2012.

${ }^{457}$ The increase was from 423 persons to 749. The report attempts to argue that better implementation of laws and a more aware public have prompted the increase of reporting victims. It also attempts to disprove a theory that only $5 \%$ of all victims will identify themselves, which would make the possible numbers of victims of sexual
} 
sex industry increases human trafficking for sexual exploitation. If men believe that it is acceptable to purchase another person to use for sex, this behavior becomes normalized. This normalization creates an increased demand, which even a legal prostitution industry cannot fulfill without "importing" more prostitutes. The resulting supply, behavior normalization, and demand pattern repeats itself. Hence legalized or regulated sex industries do nothing to prevent human trafficking; rather they increase the trade of human beings to the sex industry. ${ }^{458}$

Sweden has addressed all forms of human trafficking in its legislation. The law banning the purchase of sexual services has been effective in reducing human trafficking for sexual exploitation. There are reliable statistics available from Sweden concerning the law banning the purchase of sexual services, which are supported by qualitative assessments of the situation. This makes the critique that reliable data cannot be found void. It is true that these are based upon estimates, as virtually all human trafficking data are. The problems associated with the legislation in Sweden are mainly in regards to implementation. The legislation has been improved over the years it has been in place. If it is not perfect, the Swedish legislation recognizes the majority of problems and attempts to solve them.

Sweden views human trafficking as gender discrimination and subsequently banned prostitution. Meanwhile, Estonia does not recognize human trafficking as a gender-based crime, per se, but it is regarded as a crime which is more likely to affect women and to

exploitation much higher, at 6,080 people in 2009 and 11,960 people in 2010 . Unfortunately there is no way to prove or disprove such theories by either side. In the opinion of the author, it is more feasible that the number of self-identified victims has increased due to the increase of total victims. This is based on the nature of the crime and its effects on victims; they are often unwilling to identify themselves due to fear. The Rapporteur offered no examples of outreach campaigns which had been initiated in 2009-2010 and could have caused such an increase in identified victims. National Rapporteur on Trafficking in Human Beings and Sexual Violence against Children, "Trafficking in Human Beings: Visible and Invisible," A quantitative report 2007-2011, The Hague, 2012.

${ }^{458}$ Routhier, 14-15. 
involve prostitution. Estonian law regarding the sex industry is vague and as a social issue, prostitution is yet to be confronted by state legislation.

Estonia would make progress if it should decide to address the sex industry in the same manner that Sweden has. Following Sweden's lead by criminalizing sex purchase would likely have a favorable outcome, as it has been demonstrated that the sex industry is detrimental to gender equality as well as damaging to participants on both sides of the transaction. Prostitution is not a completely free choice for the person being purchased. In addition, virtually all prostitution is enforced and controlled by a third party or network, easily making it a part of a larger organized network of crime. The adoption of Swedishinspired criminalization legislation would support the Estonian goal of achieving a Northern European status. The location of the country, part of its history, and some cultural aspects are conducive to this change. The biggest factor against Estonia being viewed from the outside as Scandinavian is that fact that is was occupied by the Soviet Union and is often categorized as Eastern European or post-Soviet. Work on human trafficking and the mimicking of Scandinavian laws would help promote the loss of such labels.

Estonia must fully realize that human trafficking is indeed a problem in the country. This process is ongoing. Being a country that does not invest as much time or money to social issues when compared to countries such as Sweden, it is difficult to imagine the Estonian government taking the initiative for these types of change. It is more likely that NGOs and international organizations supported by members of civil society would push for further action against human trafficking. 
Unfortunately, there is a "shortage of research-based knowledge of the reasons for and the damaging effects of prostitution." ${ }^{" 459}$ If the sex industry is detrimental to women and their position in society, it is legitimate to criminalize prostitution regardless of its impact on human trafficking. However, there must be more thorough research to enable an effective strategy which addresses the needs of both the society and the individuals whom legislation would be aimed at protecting. The reasons for entrance into prostitution must also be more thoroughly investigated because, while there are some correlations on background and experiences during early life, there are also anomalies. ${ }^{460}$ The three major categories of factors appear to be "personal problems, social inequality, and drug use." ${ }^{461}$ It is clear that participation in the sex industry is preceded by multiple complex factors, which must be studied in greater depth. ${ }^{462}$ The purchasers must also be further studied, as these are the people driving the market and perpetuating criminal activities.

The formation of organizations that provide services and assistance to persons who have been or are at danger of being trafficked is imperative. In addition to being vital for victims and potential victims, such organizations are often the first to report new trends, keep statistics, inform the public, and be the driving force behind state-level amendments and formal acknowledgements. Simply confining analysis of anti-trafficking measures to action at the state level is severely limiting to the understanding of the more complex dynamics involved. At the present time, the majority of such work in Estonia and Sweden is being done by non-governmental organizations. ${ }^{463}$ The Estonian government has been

\footnotetext{
${ }^{459}$ Charlotta Holmström and May-Len Skilbrei, "Prostitution in the Nordic Countries," Conference report, Copenhagen: Nordic Council of Ministers, 2008, 24; Liu, 329.

460 Liu, 329-330.

${ }^{461}$ Holmström and Skillbrei, 35.

462 Lui, 338.

${ }^{463}$ For example, "Living for Tomorrow" in Estonia.
} 
involved in human trafficking prevention but not at the same level as the Swedish government. Governmental participation has improved, in particular regarding the legal amendments that make human trafficking a crime of its own accord and through supporting NGOs as the primary caretakers and agents of prevention.

Finally, the seemingly inexorable link between human trafficking and the "White Slave Trade" must be reconsidered. Human trafficking should be reformulated in the collective consciousness as slavery, not forced prostitution. It has become obvious through the research for this thesis that prostitution reinforces gender norms, displaces women in society, and contributes to human trafficking. The sex industry should be targeted, and the most effective method is to focus on the demand side. When combined with assistance to those who have been exploited in the sex trade this method is particularly effective. These are all necessary objectives. However, equal attention should be given to other forms of trafficking as well as how to prevent them.

There is continual improvement as more information is collected, interpreted, and used to create more effective policies. However, as human traffickers continually update their methods the means employed against trafficking must also evolve. While this endeavor will require time, determination, continued research, and resources, such sacrifices are necessary in the attempt to protect the human rights of all individuals. 


\section{Bibliography}

Primary Sources:

Arrak, Andres. "Prostitutsioon Tuleks Legaliseerida." Postimees, 12.07.2013.

http://arvamus.postimees.ee/1298238/andres-arrak-prostitutsioon-tuleks-legaliseerida

Associated Press." New UN report says human trafficking found in 118 countries, majority of victims are women." Washington Post, February 13, 2013.

Eespere, Katri. "Prostitutsiooni Legaliseerimine on Mõttetu." Postimees, 16.07.2013.

http://arvamus.postimees.ee/1301714/katri-eespere-prostitutsiooni-legaliseerimine-on-mottetu

European Commission. "The EU Strategy towards the Eradication of Trafficking in Human Beings 2012-2016." Communication from the Commision to the Parliament, the Council, the European Economic and Social Committee and the Committee of the Regions. EURLEX, June 19, 2012.

International Labour Organization. "Operational indicators of trafficking in human beings: Results from a Delphi survey implemented by the ILO and the European Commission." PDF, September 2009.

International Labour Organization." Forced labor: Coercion and exploitation in the private economy." Edited by Beate Andrees and Patrick Belser.

International Labour Organization. "International Labour Organization 2012 Global Estimate of Forced Labour." ILO Special Action Programme to Combat Forced Labour, Geneva, June 1, 2012.

International Labour Organization. "Decent Work." International Labour Organization, 2013. http://www.ilo.org/global/topics/decent-work/lang--en/index.htm (accessed April 04, 2013).

International Labour Organization. "ILO indicators of Forced Labour." October 1, 2012. http://www.ilo.org/sapfl/Informationresources/Factsheetsandbrochures/WCMS_203832/1 ang--en/index.htm (accessed January 16, 2013).

League of Nations."International Agreement for the suppression of the 'White Slave Traffic'." Paris: United Nations, May 18, 1904.

National Assembly of France. "Declaration of the Rights of Man (1789)." The Avalon Project: Documents in Law, History, and Diplomacy, Yale Law School (2008). 
National Rapporteur on Trafficking in Human Beings and Sexual Violence against Children. "Trafficking in Human Beings: Visible and Invisible. A quantitative report 2007-2011." The Hague, 2012.

NGO Living for Tomorrow. "Human Trafficking prevention and victim assistance Hotline statistics 2011." NGO Living for Tomorrow, 2012.

NGO Living for Tomorrow. "Human Trafficking prevention and victim assistance Hotline statistics 2012." NGO Living for Tomorrow, 2013.

Office to Monitor and Combat Trafficking in Persons. "Tier Placements: Trafficking in Persons Report 2011." United States Department of State, 2011.

Special Action Programme to Combat Forced Labour. " ILO Indicators of Forced Labour." PDF. Geneva: International Labour Office, October 1, 2012.

Swedish Government. "Gender equality: The Swedish Approach to Fairness."

http://www.sweden.se/eng/home/society/equality/facts/gender-equality-in-sweden/

UN General Assembly. "Convention for the Suppression of the Traffic in Persons and of the Exploitation of the Prostitution of Others." December 2, 1949.

United Nations. "International Convention for the Suppression of the White Slave Traffic." United Nations Treaty Collection, May 4, 1910.

United Nations Office on Drugs and Crime. "Global Report on Trafficking in Persons." United Nations Office on Drugs and Crime, United Nations, 2012.

United Nations Office on Drugs and Crime. "Global Report on Trafficking in Persons: Country Profiles - Europe and Central Asia." Vienna: UNDOC, 2012.

United Nations Office on Drugs and Crime. "Human Trafficking." October 30, 2008. http://www.unodc.org/unodc/en/human-trafficking/what-is-human-trafficking.html (accessed January 20, 2013).

United Nations. "Protocol to Prevent, Suppress and Punish Trafficking in Persons, Especially Women and Children, Supplimenting the United Nations Convention Against Transnational Organized Crime." New York, 2004.

United Nations. "The Universal Declaration of Human Rights." December 10, 1948. http://www.un.org/en/documents/udhr/ (accessed March 20, 2013).

United States Deartment of State. "Trafficking in Persons Report: Estonia." 2012.

United States Department of State. "Country Reports on Human Rights Practices for 2012:

Estonia." Bureau of Democracy, Human Rights and Labor, 2013. 
United States Department of State. "Trafficking in Persons Report: Countries D-I." 2012.

Wahlberg, Kajsa. "Speech by Kajsa Wahlberg, Swedish National Rapporteur on Trafficking in Human Beings at the Conference on Trafficking in Human Beings and Prostitution 'Global Problems-Local and Regional Solutions'." Copenhagen: Women's Council in Denmark, March 23, 2012.

Secondary Sources:

Alvarez, Maria Beatriz, and Edward J. Alessi. "Human Trafficking Is More Than Sex Trafficking and Prostitution: Implications for Social Work." Affilia 27, 2 (May 2012 ): 142-152.

Arnold, Denis G., and Norman E. Bowie. "Sweatshop Labor and Respect for Persons." Business Ethics Quarterly 13, 2 (2003): 221-242.

Aromaa, Kauko. "Trafficking in Human Beings: Uniform Definitions for Better Measuring and for Effective Counter-Measures" Measuring Human Trafficking. Edited by Ernesto U. Savona and Sonia Stefanizzi. New York: Springer, 2007: 13-64.

Baker, Katie J.M."Some Feminists Are Wrongfully Fighting Against Sex Workers." Jezebel, January 22, 2013.

Bandarage, Asoka. "Women in Development: Liberalism, Marxism and Marxist-Feminism." Development and Change, 1984: 495-515.

Bernstein, Elizabeth. "The Sexual Politics of the "New Abolitionism." diffe r e n c e s: A Journal of Feminist Cultural Studies, 2007: 128-151.

Bernstein, Elizabeth. "Militarized Humanitarianism Meets Carceral Feminism: The Politics of Sex, Rights, and Freedom in Contemporary Antitrafficking Campaigns." Signs, Autumn 2010: 45-71.

Bernstein, Laurie. Sonia's Daughters: Prostitutes and Their Regulation in Imperial Russia. Berkeley: University of California Press, 1995. http://ark.cdlib.org/ark:/13030/ft9199p2dt/

Besler, Patrick. "Forced Labor and Human Trafficking: Estimating the Profits." International Labour Organization, Vienna: March 2005.

Bindel, Julie. "Why even Amsterdam doesn't want legal brothels: The Dutch experiment in legalised prostitution has been a disaster." The Spectator, February 2, 2013. 
Bowie, Norman. "Business Ethics: A Kantian Perspective." Wiley-Blackwell, 1999.

Butler, Judith. Gender Trouble. New York: Routledge, 1999.

Carael, M., E. Slaymaker, R. Lyerla, and S. Sarkar. "Clients of sex workers in different regions of the world: hard to count." Sexually Transmitted Infections 82 (June 2006): ii26-ii33.

Cho, S.-Y., A. Dreher, and E. Neumayer. "Does Legalized Prostitution Increase Human Trafficking? Economics of Security Working Paper 71." World Development, January 2013: 67-82.

Cho, Seo-Young, and Krishna Chaitanya Vadlamannati. "Compliance with the Anti-trafficking Protocol." European Journal of Political Economy, June 2012: 249-265.

Crowhurst, Isabel, Joyce Outshoorn, and May Skilbrei. "Introduction: Prostitution Policies in Europe." Sexuality Research and Social Policy 9, 3 (September 2012): 187-191.

Crowhurst, Isabel, Joyce Outshoorn, and May-Len Skilbrei. "Introduction: Prostitution Policies in Europe." Sexuality Research and Social Policy 9, 3 (September 2012): 187-191.

Dawson, John P."Economic Duress: An Essay in Perspective." Michigan Law Review 45, 3 (1947): 253-290.

Dodillet, Susanne and Petra Östergren. "The Swedish Sex Purchase Act: Claimed Success and Documented Effects." The Hague, March 3 \& 4, 2011.

Doezema, Jo. "Who Gets to Choose? Coercion, Consent, and the UN Trafficking Protocol." Gender and Development 10, 1 (March 2002): 20-27.

Eespere, Katri. "Combatting Trafficking in Persons in Estonia: Experts Opinions about Problems and Solutions." Estonian Women's Studies and Resource Centre, Nordic Council of Ministers, 2004.

Eespere, Katri. "The hidden side of prostitution: sex buyers speak." Research Report. Social Policy Information and Analysis Department, Ministry of Social Affairs of the Republic of Estonia, 2007.

Ekberg, Gunilla. "The Swedish Law That Prohibits the Purchase of Sexual Services: Best Practices for Prevention of Prostitution." Violence Against Women 10, 10 (October 2004 2004): 1187-1218.

Englestein, Laura. "Gender and the Juridical Subject: Prostitution and Rape in Nineteenth-Century Russian Criminal Codes." The Journal of Modern History 60, 3 (Sep., 1988): 458-495. 
Englund, Cecilia, et al. "The Organisation of Human Trafficking: A Study of Criminal Involvement in Sexual Exploitation in Sweden, Finland and Estonia." Swedish National Council for Crime Prevention (Brottsförebyggande rådet - Brå), 2008.

Estonian Ministry of Foreign Affairs."Estonia to Head Nordic-Baltic Co-operation Programme." Estonian Review, December 2, 2012.

Estrada, Felipe, Tove Pettersson, and David Shannon. "Crime and Criminology in Sweden." European Journal of Criminology 9, 6 (2012): 668-688.

Farley, Melissa. " 'Bad for the Body, Bad for the Heart': Prostitution Harms Women Even if Legalized or Decriminalized." Violence Against Women 10 (2004).

Farley, Melissa. "Prostitution Harms Women Even if Indoors: Reply to Weitzer." Violence Against Women 11 (2005).

Foerster, Susanne. "National Prostitution Legislation and its Impact on the Fight against Trafficking in Women for Sexual Purposes in the European Union." Master Thesis. University of Twente, 2011.

Fouché, Gwladys. " 'Sex ban puts us at greater risk'." The Guardian, May 27, 2009.

Fox, Edward. "Desperation, Lack of Donors Drives Organ Trafficking in Latin America." July 6, 2012. http://www.insightcrime.org/news-analysis/desperation-lack-of-donors-drivesorgan-trafficking-in-latin-america (accessed June 19, 2013).

Gelb, Joyce. Feminism and Politics: A Comparative Perspective. Berkeley: University of California Press, 1989. http://ark.cdlib.org/ark:/13030/ft3z09n8wj/

Gould, Chandré."Trafficking? Exploring the relevance of the notion of human trafficking to describe the lived experience of sex workers in Cape Town, South Africa." Crime, Law, and Social Change, November 2011.

Grant, Melissa Gira. "The War on Sex Workers." Reason, February 2013: 30-36.

Haug, Frigga. "Sexual deregulation or, the child abuser as hero in neoliberalism." Feminist Theory 2, 1 (2011): 55-78.

Hedin, Ulla-Carin, and Sven Axel Månsson. "The Importance of Supportive Relationships Among Women Leaving Prostitution." Journal of Trauma Practice, July 1, 2002: 223237.

Heinrich, Kelly Hyland. "Ten Years After the Palermo Protocol: Where are Protections for Human Trafficking Victims?" Human Rights Brief, 2010. 
Helemäe, Jelena, and Ellu Saar. "Estonia - Highly Unequal but Classless?" Studies of Transition States and Societies 4, 2 (November 2012): 49-58.

Herman, Sondra R. "Children, Feminism, and Power: Alva Myrdal and Swedish Reform." Journal of Women's History 4, 2, Fall 1992:82-112.

Herzfeld, Beth. "Slavery and Gender: Women's Double Exploitation." Gender and Development, March 2002: 50-55.

Høigård, Cecilie, and Liv Finstad. "Bakgater: om prostitusjon, penger og kjaerlighet (Backstreets-on prostitution, money and love)." Oslo: Pax förlag, 1986.

Hoag, John and Mark Kasoff. "Estonia in Transition." Journal of Economic Issues 33, 4 (Dec. 1999): 919-931.

Holligan, Anne. "Can Amsterdam clean up the red light district?" BBC, July 5th, 2012.

Holmström, Charlotta, and May-Len Skilbrei. "Prostitution in the Nordic Countries." Conference report. Copenhagen: Nordic Council of Ministers, 2008.

Huda, Sigma. "Prostitution: A Profitable Form of Trafficking and the Mechanisms to Counter It." Pakistan Journal of Women's Studies: Alam-e-Niswan 16, 1\&2 (2009): 235-254.

Human Trafficking Foundation. "Domestic Servitude." n.d. http://www.humantraffickingfoundation.org/whats-issue/case-studies/domestic-servitude (accessed June 20, 2013).

Ibrus, Kadri. "Inimkaubitseja Indrek Mandre Luksemburgi äripartnereid ähvardab aastatepikkune vangistus." Eesti Päevaleht, August 28, 2009.

ILO Newsroom. "21 million people are now victims of forced labour, ILO says." International Labour Organization, June 01, 2012.

International Organization for Migration "Trafficking in Women and Prostitution in the Baltic States: Social and Legal Aspects.” January 1, 2001. ISBN-10: 9290681179

Järviste, Liina. "Gender Equality and Inequality: Attitudes and Situation in Estonia in 2009." Ministry of Social Affairs, 3/2010.

Jokinen, Anniina, Natalia Ollus, and Kauko Aromaa. "Trafficking for Forced Labour and Labour Exploitation in Finland, Poland and Estonia." Helsinki: European Institute for Crime Prevention and Control, affiliated with the United Nations; United Nations Office on Drugs and Control, 2011. 
Jordan, Anne. "The Swedish Law to Criminalize Clients: A Failed Experiment in Social Engineering." April 2012.

Kask, Maris, and Anna Markina. "Trafficking for Forced Labour and Labour Exploitation in Estonia." In Trafficking for Forced Labour and LabourExploitation in Finland, Poland and Estonia, edited by Anniina Jokinen, Natalia Ollus and Kauko Aromaa, 246-308. Helsinki: Prevention of and Fight against Crime, 2011.

Kerr, Rachel Bezner, and Paul Mkandawire. "Imaginative geographies of gender and HIV/AIDS: moving beyond neoliberalism." GeoJournal 77, 4 (August 2012 ): 459-473.

Laar, Mart. “Deportation from Estonia in 1941 and 1949." Estonia Today, Estonian Ministry of Foreign Affairs, June 2006.

Lauristin, Marju, Peeter Vihalemm, Kark Erik Rosengren, and Lennart Weibull. Return to the Western World: Cultural and Political Perspectives on the Estonian Post-Communist Transition. Tartu: Tartu University Press, 1997.

Levy, Ariel. Female Chauvinist Pigs. New York: Free Press, 2006.

Limoncelli, Stephanie A. "The trouble with trafficking: Conceptualizing women's sexual labor and economic human rights." Women's Studies International Forum, 2009: 261-269.

Liu, Min. "Chinese Migrant Women in the Sex Industry: Exploring Their Paths to Prostitution." Feminist Criminology, September 16, 2012: 327-349.

Long, Eric. "Revealing the Realities of Trafficking: A Conversation with E. Benjamin Skinner." Journal of International Peace Operations 7, 6 (2012): 21-25.

Lundberg, Urban and Klas Amark. "Social Rights and Social Security: The Swedish Welfare State 1900-2000.” Scandinavian Journal of History 26, 3: 157-176.

Mamonova, Tatyana. "USSR: Perestroika, Pornography, and Prostitution.” GenderWatch 2, 2 (Sept. 1991): 12.

Marcelin, Louis Herns. "Slavery." In Encyclopedia of Anthropology, edited by H. James Birx, 2091-93. Thousand Oaks, CA: 2006.

Marinova, Nadejda K., and Patrick James. "The Tragedy of Human Trafficking: Competing Theories and European Evidence." Foreign Policy Analysis, July 2012: 231-253.

Martinez, Jenny S. "The Slave Trade and the Origins of International Human Rights Law." Stanford Lawyer, 85 (October 2011).

Merriam-Webster's Geographical Dictionary. "Estonia." Accessed October 25, 2013. 
Metaphysics Research Lab (The). " Kant's Moral Philosophy." Edited by Edward N. Zalta, April 6, 2008. http://plato.stanford.edu/entries/kant-moral/\#HumFor (accessed March 20, 2013).

McHugh, Nancy Arden. "Feminist Philosophies A-Z; Marxist Feminism." Credo Reference, 2007.

http://www.credoreference.com.www.libproxy.wvu.edu/entry/edinburghfem/marxist_fem inism (accessed 04 14, 2013).

Ministry of Industry, Employment, and Communications. "Prostitution and Trafficking in Human Beings." Stockholm: Ministry of Industry, Employment and Communications, Division for Gender Equality, April 2005.

Mosher, Nicole Bianchini. "Impressions of Gender in International Anti Human Trafficking Instruments: Hegemonic Gender Inequality in Europe and Beyond." Ann Arbor: December 2011.

Nason, Erica E., and Elizabeth A. Yeater. "Sexual Attitudes Mediate the Relationship Between Sexual Victimization History and Women's Response Effectiveness." Journal of Interpersonal Violence 27, 13 (February 2012): 2565-2581.

Nautz, Jürgen. "The Effort to Combat the Traffic in Women in Austria before the First World War." Journal for Police Science and Practice, 2: 82-95.

Nesbitt, Nick. Universal Emancipation: the Haitian Revolution and the Radical Enlightenment. Charlottesville: University of Virginia Press, 2008.

Nordic Baltic Task Force Against Trafficking in Human Beings. "The Organisation of Human Trafficking: A Study of Criminal Involvement in Sexual Exploitation in Sweden, Finland and Estonia." Stockholm: Swedish National Council for Crime Prevention (Brottsförebyggande rådet - Brå), n.d.

O'Brien, Erin. "Fuelling Traffic: Abolitionist Claims of a Causal Nexus Between Legalised Prostitution and Trafficking." Crime, Law and Social Change 56, 5 (December 2011): 547-565.

Outshoorn, Joyce."The Political Debates on Prostitution and Trafficking of Women." Social Politics: International Studies in Gender, State and Society 12, 1, Spring 2005 (2005): 141-155.

Pajumets, Marion."Prostitutsioon - kas ühiskondlik probleem? Arvamused nähtuse olemusest, põhjustest, tagajärgedest [Prostitution - a social problem? Views on its nature, causes and effects]." Translated by Ilvi Jõe-Cannon. Tallinn: Eesti Naisuurimus- ja Teabekeskus, EV Sotsiaalministeeriumi võrdõiguslikkuse osakond, Põhjamaade Min, 2004. 
Panagiotou, R.A."Estonia's Success: Prescription or Legacy?" Communist and Post-Communist Studies 34 (2000): 261-277.

Parts, Juhan. "Estonia and the European Debt Crisis." Cato Journal 33, 2: 269-274.

Pates, Rebecca. "Liberal Laws Juxtaposed with Rigid Control: an Analysis of the Logics of Governing Sex Work in German." Sexuality Research and Social Policy 9, 3 (September 2012): 212-222.

Pattenden, Jonathan. "Forced Labor: Coercion and Exploitation in the Private Economy." Edited by Beate Andrees and Patrock Belser. Journal of Agrarian Change 11, 3 (July 2011): 447-449.

Peck, Gunther. "White Slavery and Whiteness: A Transnational View of the Sources of Working-Class Radicalism and Racism." Labor: Studies in Working-Class History of the Americas 1, 2 (2004): 41-63.

Perry, Mark J. "Donor Compensation, Not Kidney Swaps, is the Only Solution to Growing Kidney Shortage in U.S." Carpe Diem, February 19, 2012.

Pettai, Iris, Helve Kase, and Ivi Proos. "Prostitution in Estonia: a Survey of the Situation of Women Involved in Prostitution. Results of a sociological study." Tallinn: Eesti Avatud Ühiskonna Instituut [Estonian Institute for Open Society], 2006.

Pliley, Jessica R. "Claims to Protection: The Rise and Fall of Feminist Abolitionismin the League of Nations' Committee on the Traffic in Womenand Children, 1919-1936" Journal of Women's History 22, 4 (2010): 90-113.

Polaris Project. "Labor Trafficking of Domestic Workers At-A-Glance." Polaris Project: National Human Trafficking Resource Center, 2011.

Polaris Project. "Myths and Misconceptions." 2013. http://www.polarisproject.org/humantrafficking/overview/myths-and-misconceptions (accessed Febrary 4, 2013).

Polaris Project. "The Victims." 2013. http://www.polarisproject.org/humantrafficking/overview/the- "victims (accessed February 04, 2013).

Popkin, Jeremy D. A History ofMmodern France. Englewood Cliffs: Prentice Hall, 1994.

Popkin, Jeremy D. You Are All Free: The Haitian Revolution and the Abolition of Slavery. Cambridge: Cambridge University Press, 2010.

Poudel, Meena, and Ines Smyth. "Reducing Poverty and Upholding Human Rights: A Pragmatic Approach." Gender and Development 10, 1 (March 2002): 80-86.

Raud, Villibald. Estonia - A Reference Book. New York: Nordic Press, 1953. 
Raymond, Janice G. "Guide to the New UN Protocol." Coalition Against Trafficking in Women, 2001.

Ribeiro, Emma Stenberg." Human Trafficking and Prostitution from a Swedish Perspective." County Administrative Board of Stockholm; National Task Force Against Prostitution and Human Trafficking (NMT), 2011.

Ricardo, Christine, and Gary Barker. "Men, Masculinities,Sexual Exploitation and Sexual Violence: A Literature Review and Call for Action." Promundo and MenEngage, Rio de Janeiro: 2008.

Rössborn, Stella. "Estonia: Report on Cooperation Between Stakeholders at the National Level in Estonia to Address Trafficking for Labour Exploitation." Peace and Security Consulting for Task Force Against Trafficking in Human Beings of the Council of the Baltic Sea States, 2012.

Routhier, Giselle. "Understanding The Demand For Human SexTrafficking: A Study Of Attitudes Regarding The Commercial Sex Industry." Social Work Theses, Paper 11, Providence College, April 24, 2007.

Sage, Jesse and Liora Kasten. Enslaved: True Stories of Modern Day Slavery. Palgrave Macmillan, 2006.

Sallmann, Jolanda. "Living With Stigma: Women's Experiences of Prostitution and Substance Use." Affilia 25, 2 (2010): 146-159.

Schneewind, J. B. , Marcia Baron, Shelly Kagan, and Allen W. Wood. Groundwork for the Metaphysics of Morals: Immanuel Kant. Edited by Allen W. Wood. Translated by Allen W. Wood. New Haven and London: Yale University Press, 2002.

Shubert, Atika. "The Battle Against Sex Trafficking: Sweden vs. Denmark." News Article. CNN, March 30, 2011.

Skrivankova, Klara. "Between Decent Work and Forced Labour: Examining the Continuum of Exploitation." JRF programme paper. Joseph Rowntree Foundation, York: 2010.

Snyder, Jeremy. "Exploitation and Sweatshop Labor: Perspectives and Issues." Business Ethics Quarterly 20, Issue 2 (April 2010): 187-213.

Stites, Richard." Prostitute and Society in Pre-Revolutionary Russia." Jahrbücher für Geschichte Osteuropas, Neue Folge 31, 3 (1983): 348-364.

Steinfeld, Robert. "Coercion/Consent in Labour: Working Paper No. 66." University of Oxford, Oxford: Centre on Migration, Policy and Society, 2009.

Sterner, Gunilla. "Gender Equality Policy in Sweden.” Ministry of Integration and 
Gender Equality, n.d.

Strauss, Kendra. "Coerced, Forced and Unfree Labour: Geographies of Exploitation in Contemporary Labour Markets." Geography Compass 6, 3 (March 2012): 137-148.

Strøm, Agneta. "A Glimpse into 30 Years of Struggle Against Prostitution by the Women's Liberation Movement in Norway." Reproductive Health Matters 17, 34 (2009): 29-37.

Summers, Anne. "Which Women? What Europe? Josephine Butler and the International Abolitionist Federation." History Workshop Journal 62 (Autumn 2006): 214-231.

Svensson, Eva-Maria, and Asa Gunnarsson. "Gender Equality in the Swedish Welfare State." feminists@law2,1,2012.

Swedish Institute."Selected Extracts of the Swedish Government Report SOU 2010:49: The Ban Against the Purchase of Sexual Services. An Evaluation 1999-2008." Policy Evaluation. Swedish Institute, Stockholm, 2010.

Swedish National Police Board. "Trafficking in Human Beings for Sexual and Other Purposes." Situation report (Lägesrapport). PVS Information Unit, Swedish National Police Board, 2011.

Taagepera, Rein. "Soviet Collectivization of Estonian Agriculture: The Deportation Phase." Soviet Studies 32, 3 (Jul., 1980): 379-397.

Tracy, Erin E., and Wendy Macias Konstantopoulos. "Human Trafficking: A Call for Heightened Awareness and Advocacy by Obstetrician-Gynecologists." The American College of Obstetricians and Gynecologists 119, 5 (May 2012): 1045-1047.

Tzvetkova, Marina. "NGO Responses to Trafficking in Women." Gender and Development, March 2002: 60-68.

Ummelas, Ott. "Why Estonia Loves the Euro.” Business Week, February 2, 2012.

Viuhko, Minna. "Human Trafficking for Sexual Exploitation and Organized Procuring in Finland." European Journal of Criminology 7, 1 (2010): 61-75.

Waugh, Louisa. Selling Olga: Stories of Human Trafficking and Resistance. London: Phoenix, 2007.

Waltman, Max. "Sweden's Prohibition of Purchase of Sex: The Law's Reasons, Impact, and Potential." Women's Studies International Forum 34, 5, September-October (2011,): $449-474$.

Waters, Elizabeth.” Restructuring the 'Woman Question': Perestroika and Prostitution.” Feminist Review 33 (Autumn, 1989): 3-19. 
Weitzer, Ronald."Sociology of Sex Work." Annual Review of Sociology, February 19, 2009: 213-234.

Weitzer, Ronald. "Sex Trafficking and the Sex Industry: The Need for Evidence-Based Theory and Legislation." The Journal of Criminal Law \& Criminology 101, 4 (2012): 1337-1369.

Wennerholm, Carolina Johansson."Crossing Borders and Building Bridges: The Baltic Region Networking Project." Gender and Development 10, 1 (March 2002): 10-19.

Wheaton, Elizabeth M., Edward J. Schauer, and Thomas V. Galli. "Economics of Human Trafficking." International Migration, 2010, 114-141.

Willams, Sophie, Lenore Lyons, and Michele Ford. "It's About Bang for Your Buck, Bro: Singaporean Men's Online Conversations about Sex in Batam, Indonesia." Asian Studies Review 32 (March 2008): 77-97.

Zelizer, Viviana A. "The Purchase of Intimacy." Law \& Social Inquiry 25, 3 (2000): 817-848.

Zhang, Sheldon X. "Measuring Labor Trafficking: a Research Note," Crime, Law and Social Change 58 (November 2012): 469-482.

Zimmerman, Cathy, Mazeda Hossain, Kate Yun, Brenda Roche, Linda Morison, and Charlotte Watts. "Stolen smiles: a Summary Report on the Physical and Psychological Health Consequences of Women and Adolescents Trafficked in Europe." The London School of Hygiene \& Tropical Medicine, 2006. 